\title{
Medical Radioisotopes Production: A Comprehensive Cross-Section Study for the Production of Mo and Tc Radioisotopes Via Proton Induced Nuclear Reactions on ${ }^{\text {nat }}$ Mo
}

\author{
A. A. Alharbi ${ }^{1,2}$ et al. ${ }^{*}$ \\ ${ }^{1}$ Faculty of Sciences, Physics Department, \\ Princess Nora University Riyadh, \\ ${ }^{2}$ Cyclotron institute, Texas AEM University, \\ College Station, TX, \\ ${ }^{1}$ Saudi Arabia, \\ ${ }^{2}$ USA
}

\section{Introduction}

\subsection{Radioisotopes in nuclear medicine}

Nowadays, many different stable and radioactive isotopes, each with unique physical and chemical properties, play significant roles in technological applications of importance to our modern society and are substantial to scientific research. One of the most common applications is the use of the radioisotopes in medicine. Medical radioisotopes are used to label some special chemical compounds to form radiopharmaceuticals.

Radiopharmaceuticals are used extensively in the field of nuclear medicine in three main branches. The largest and the most common type involve diagnostic procedures in which a radionuclide in a chemically suitable form is administered to the patient, and the distribution of the radioactivity in the body is determined by an external radiation detector (Qaim, 2008). The results are in the form of image of the involved organ, which provides information about the functioning of person's specific organs via emission tomography. The second branch of nuclear medicine deals with radionuclide techniques that are used for the analysis of concentration of hormones, antibodies, drugs and other important substances in samples of blood or tissues. The third branch is radiation therapy, which is the ultimate aim of all diagnostic investigations. Here the tissues or organs are treated with radiation and restored to the normal functions in the human body (Loveland, et al., 2006).

*A. Azzam¹,3, M. McCleskey², B. Roeder², A. Spiridon², E. Simmons ${ }^{2}$, V.Z. Goldberg', A. Banu', L. Trache ${ }^{2}$ and R. E. Tribble ${ }^{2}$

${ }^{1}$ Faculty of Sciences, Physics Department, Princess Nora University Riyadh, Saudi Arabia,

${ }^{2}$ Cyclotron institute, Texas AEM University, College Station, TX, USA

${ }^{3}$ Nuclear Physics Department., Nuclear Research Center, AEA, Cairo, Egypt 
The two fundamental considerations in the administration of radioactivity to the human body are (Krane, 1987):

- Efficient detection of the radiation from outside the body,

- Radiation dose caused to the patient.

Diagnostic techniques in nuclear medicine use radioactive tracers which are easily detectable and which help to investigate various physiological and metabolic functions of the human body. Diagnosis is usually conducted by short-lived radionuclides, generally attached to a suitable chemical compound. Depending on the nature of the radiopharmaceutical, it may be inhaled, ingested, or injected intravenously (Stócklin, et al., 1995). The radiation emitted by the radionuclide provides different kinds of information, as required for diagnosis. Radionuclides are powerful tools for diagnosis due to three reasons:

1. The mass of the sample is infinitesimally small, as low as $10^{-10} \mathrm{~g}$ of radioactive material, so it does not disturb the biological equilibrium.

2. The radioactive form of an element behaves exactly the same way as the nonradioactive element.

3. Each radioactive material spontaneously decays into some other form with emission of radiation. This radiation can be detected from outside the body.

Depending upon the nature of radionuclide, today two different tomographic procedures are available for imaging:

- $\quad$ Single photon emission computed tomography (SPECT)

- $\quad$ Positron emission tomography (PET)

In SPECT, a single or a dominant photon is detected by a gamma camera, which can view organs from many different angles (Khan, 2003). The camera makes an image from the points where the radiation is emitted; this image achieved by the camera is enhanced on a computer and can be viewed by a physician.

Positron Emission Tomography (PET) is a more modern technique in which a positronemitting radionuclide, attached to a proper chemical compound, is introduced in the body, usually by injection, where it accumulates in the target tissue. As it decays it emits a positron, which at first loses its kinetic energy in the tissue and then promptly combines with a nearby electron resulting in the simultaneous emission of two identifiable photons in opposite directions $\left(180^{\circ}\right)$. These are detected by two detectors in coincidence. An array of such detectors is known as a PET camera, it gives very precise and sophisticated information on the place of annihilation. The most important clinical role of PET is in oncology, with a suitable fluorine-18 labelled compound as the tracer, since it has been found to be the best non-invasive method of detecting and evaluating most cancers. It is also well used in cardiac and brain imaging (Qaim, et al., 1993).

The radiation therapy is often done by using external beams of protons, neutrons, electrons, or photons (Wolf \& Jones, 1983). As far as radionuclides are concerned, there are many possibilities to utilize them in therapy. One such possibility is to use the radiation emitted by the radionuclides, e.g. electrons and high-energy $\gamma$-rays as in the case of ${ }^{60} \mathrm{Co}$. However, in recent years internal radiotherapy has also been gaining enhanced attention. Internal radiotherapy involves the use of radionuclides of suitable decay characteristics (Qaim, 2003). When a therapeutic radionuclide is delivered to a specific organ by using a biochemical pathway, it is known as open source therapy or endoradiotherapy (Qaim, 2003; Krane, 1987; Wolf \& Barclay Jones, 1983). This type of 
radiotherapy is a unique cancer treatment modality. It is systemic and non-invasive. The uptake and retention in the tumour can be assessed with a tracer study before administering a therapeutic dose to the patient.

The major criteria for the choice of a radionuclide for endotherapeutic use are suitable decay characteristics and suitable biochemical reactivity. Concerning the decay properties, the desired half-life is between 6 hours and 7 days and the emitted corpuscular radiation should have a suitable linear energy transfer (LET) value and range in the tissue (Qaim, 2003; Sharp, et al., 2005). The ratio of non-penetrating to penetrating radiation should be high. The daughter should be short-lived or stable. The stability of the therapeutically pharmaceutical is demanded over a much longer period than that in the case of a diagnostic pharmaceutical. Thus, the choice falls on about 30 radionuclides. Most of them are $\beta$ - emitters but several of them are $\alpha$ emitters and Auger electron emitters.

\subsection{Medical radioisotopes production}

The main processes to produce the medical radioisotopes are neutron activation, nuclear fission, charged particles induced reactions and radionuclide generators. Mostly, chemical separation is needed to separate the required isotope from targets and any produced impurities before using in the labeling process.

The medical radioisotopes can be produced using nuclear reactors either by neutron activation or by nuclear fission. The first procedure depends mostly on the thermal neutron capture process $(n, \gamma)$. These isotopes will decay by means of $\beta$ - emission accompanied with some gamma rays and could be used in treatment or Single Photon Emission Computed Tomography (SPECT). The second procedure based on the fission of a heavy nucleus, from the fuel after thermal neutron absorption. Some of the produced fission fragments have found medical applications such as ${ }^{99} \mathrm{Mo}$ (used as ${ }^{99} \mathrm{Mo} /{ }^{99} \mathrm{mTc}$ generator), ${ }^{131} \mathrm{I}$, and ${ }^{133} \mathrm{Xe}$ (Qaim, 2004).

Charged particle accelerators are another tool for producing medical radioisotopes using charged particle induced reactions on some stable isotopes. The accelerators used for this purpose should deliver ion beam with enough energy suitable for the used nuclear reaction and high beam intensity for production of reasonable radioactive yield in a reasonable irradiation time. Usually cyclotron accelerators with energies in the range 10 to $50 \mathrm{MeV}$ are suitable for this purpose.

Cyclotron radionuclide production involves various constraints. First, a target has to be prepared, quite often from isotopically enriched material and energy should be carefully chosen to reduce, as much as possible, the impurities level. Second, the target should be stable in respect to ionizing radiation and heat generated by slowing down of the charged particles. Therefore, targets should be as thin as possible, just enough to degrade the incident energy to the required threshold energy, and they should display good heat conductivity to allow efficient cooling. After irradiation, the target is dissolved and various radiochemical operations are performed to isolate and purify the radionuclide.

The produced isotopes will usually be neutron deficient. This type of isotopes decay with $\beta^{+}$ and/or EC accompanied with specific gamma rays and can be used for Positron Emission Tomography (PET) such as ${ }^{11} \mathrm{C},{ }^{15} \mathrm{O},{ }^{13} \mathrm{~N}$, and ${ }^{18} \mathrm{~F}$ or SPECT such as ${ }^{111} \mathrm{I},{ }^{67} \mathrm{Ga}$ and ${ }^{201} \mathrm{Tl}$ (Lamberecht, 1979; Qaim, 2001). A number of isotopes as shown in Table 1 are technically available for use in medical applications (Troyer \& Schenter, 2009). 


\begin{tabular}{|c|c|c|}
\hline Purpose & Accelerator-produced & Reactor-produced \\
\hline $\begin{array}{l}\text { Therapeutic } \\
\text { Isotopes }\end{array}$ & $\begin{array}{l}{ }^{64} \mathrm{Cu},{ }^{67} \mathrm{Cu},{ }^{77} \mathrm{Br},{ }^{88 m} \mathrm{Br},{ }^{88} \mathrm{Y},{ }^{89} \mathrm{Zr},{ }^{103} \mathrm{Pd}, \\
{ }^{111} \mathrm{In},{ }^{124} \mathrm{I},{ }^{186} \mathrm{Re},{ }^{211} \mathrm{At}\end{array}$ & $\begin{array}{l}{ }^{32} \mathrm{P},{ }^{47} \mathrm{Sc},{ }^{60} \mathrm{Co},{ }^{64} \mathrm{Cu},{ }^{67} \mathrm{Cu},{ }^{89} \mathrm{Sr},{ }^{90} \mathrm{Sr},{ }^{90} \mathrm{Y}, \\
103 \mathrm{Pd},{ }^{103} \mathrm{Ru},{ }^{106} \mathrm{Ru},{ }^{109} \mathrm{Cd},{ }^{109} \mathrm{Pd},{ }^{117} \mathrm{mSn}, \\
{ }^{115} \mathrm{Cd},{ }^{125} \mathrm{I},{ }^{131} \mathrm{I},{ }^{137} \mathrm{Cs},{ }^{145} \mathrm{Sm},{ }^{153} \mathrm{Sm},{ }^{165} \mathrm{Dy}, \\
\\
{ }^{166} \mathrm{Dy},{ }^{166} \mathrm{Ho},{ }^{169} \mathrm{Er},{ }^{169} \mathrm{Yb},{ }^{180} \mathrm{Tm},{ }^{175} \mathrm{Yb},{ }^{177} \mathrm{Lu}, \\
{ }^{186} \mathrm{Re},{ }^{188} \mathrm{Re},{ }^{192} \mathrm{Ir},{ }^{195 m} \mathrm{Pt},{ }^{198} \mathrm{Au},{ }^{199} \mathrm{Au},{ }^{211} \mathrm{At}, \\
\\
{ }^{13} \mathrm{Bi},{ }^{225} \mathrm{Ac},{ }^{241} \mathrm{Am}\end{array}$ \\
\hline $\begin{array}{l}\text { Diagnostic } \\
\text { Isotopes }\end{array}$ & $\begin{array}{l}{ }^{11} \mathrm{C},{ }^{13} \mathrm{~N},{ }^{15} \mathrm{O},{ }^{18} \mathrm{~F},{ }^{55} \mathrm{Fe},{ }^{57} \mathrm{Co},{ }^{61} \mathrm{Cu}, \\
{ }^{64} \mathrm{Cu},{ }^{67} \mathrm{Ga},{ }^{74} \mathrm{As},{ }^{76} \mathrm{Br},{ }^{81 \mathrm{~m}} \mathrm{Kr},{ }^{82 \mathrm{~m}} \mathrm{Rb}, \\
{ }^{94 \mathrm{~m}} \mathrm{Tc},{ }^{97} \mathrm{Ru},{ }^{111} \mathrm{In},{ }^{123},{ }^{124} \mathrm{I},{ }^{179} \mathrm{Ta},{ }^{201} \mathrm{Tl}\end{array}$ & $\begin{array}{l}{ }^{3} \mathrm{H},{ }^{14} \mathrm{C},{ }^{51} \mathrm{Cr},{ }^{64} \mathrm{Cu},{ }^{97} \mathrm{Ru},{ }^{99 \mathrm{~m}} \mathrm{Tc},{ }^{123} \mathrm{I},{ }^{131} \mathrm{I},{ }^{133} \mathrm{Xe}, \\
{ }^{153} \mathrm{Gd},{ }^{195 \mathrm{mPt}}\end{array}$ \\
\hline
\end{tabular}

Table 1. Common medical isotopes sorted by use category and production method (Troyer \& Schenter, 2009)

\subsection{Molybdenum and technetium in nuclear medicine}

Molybdenum is used as a target material for the production of medically important

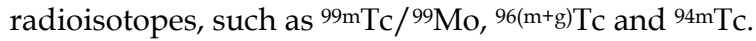

94mTc (52min), has shown its applicability as a PET isotope (Rösch and Qaim, 1993; Nickles, et al., 1993; Sajjad and Lambrecht, 1993; Rösch, et al., 1994; Fabbender, et al., 1994; Qaim, 2000; Hohn, et al., 2008). ${ }^{96} \mathrm{Tc}$ (4.28d) has been proposed for the use in prevention of coronary restenosis by Fox (2001). Despite of favorable moderate half-life, other isotopes of technetium, like, ${ }^{93} \mathrm{Tc}(2.75 \mathrm{~h}),{ }^{94} \mathrm{Tc}(4.883 \mathrm{~h})$ and ${ }^{95} \mathrm{Tc}(20.0 \mathrm{~h})$ are seldom discussed. Specially, radiological half-life of ${ }^{94} \mathrm{Tc}$ is ideal for diagnostic purposes. ${ }^{95} \mathrm{Tc}(20.0 \mathrm{~h})$, due to its comparatively longer half-life is also promising for tracking long processes, like, metabolic pathways for brain and heart, studies with proteins, anti bodies, etc. Among short-lived radionuclides, ${ }^{93} \mathrm{Tc}(2.75 \mathrm{~h})$ is another promising isotope for imaging as suggested by (Lambrecht and Montner, 1982).

One of the most important medical radioisotopes is ${ }^{99} \mathrm{mTc}\left(\mathrm{T}_{1 / 2}=6.01 \mathrm{~h}\right)$, which has a gamma ray energy of about $140 \mathrm{keV}$. The fact that both its physical half-life and its biological halflife are very short, as seen in Table 2, leads to a very fast clearing from the body after an imaging process. A further advantage is that the gamma is a single energy, not accompanied by beta emission, and that permits a more precise alignment of imaging detectors.

\begin{tabular}{cccc}
\hline \multirow{2}{*}{ Isotope } & \multicolumn{3}{c}{ Half-lives in days } \\
\cline { 2 - 4 } & $\mathrm{T}_{\text {Physical }}$ & $\mathrm{T}_{\text {Biological }}$ & $\mathrm{T}_{\text {Effective }}$ \\
99mTc & 0.25 & 1 & 0.20 \\
\hline
\end{tabular}

Table 2. The physical, biological and effective half lives for ${ }^{99 \mathrm{mTc}}$

$99 \mathrm{mTc}$ is a vital part of diagnostic tests for heart diseases and cancers; It accounts for over $80 \%$ of all diagnostic nuclear medicine procedures worldwide. According to the latest survey, the world demand for production of ${ }^{99} \mathrm{Mo} / 99 \mathrm{mTc}$ is estimated to be around 7 $\mathrm{kCi}$ /week and further growth is predicted (Takács, et al., 2003). Currently, only five nuclear reactors produce ${ }^{99} \mathrm{Mo} /{ }^{99} \mathrm{mTc}$ leading to a predicted shortage in covering the world demand. Consequently, many studies nowadays concentrate on producing ${ }^{99} \mathrm{Mo}$ generators with an alternative method using cyclotron accelerators (Van der Marck, 2010; Gull, 2001). 
${ }^{99 \mathrm{mTc}}$ is obtained from the decay of its parent isotope ${ }^{99} \mathrm{Mo}$. It was discovered in 1937, and the first ${ }^{99} \mathrm{Mo} /{ }^{99} \mathrm{mTc}$ generator was invented at the Brookhaven National Laboratory in the U.S. in 1957. General usage of $99 \mathrm{mTc}$ began in the early seventies when the Chalk River Laboratory established routine production of ${ }^{99} \mathrm{Mo}$, its parent isotope (Tammemagi and

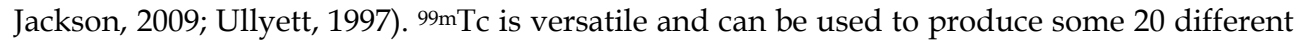
compounds of radiopharmaceuticals. There are various technological options for the

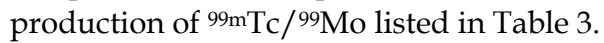

\begin{tabular}{|c|c|c|}
\hline \multirow{2}{*}{ 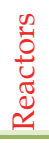 } & Fission of $235 \mathrm{U}$ & $\mathrm{n}+235 \mathrm{U} \rightarrow{ }^{99} \mathrm{Mo}+\mathrm{xn}+$ other fission products \\
\hline & Neutron activation of ${ }^{98} \mathrm{Mo}$ & $\mathrm{n}+{ }^{98} \mathrm{Mo} \rightarrow{ }^{99} \mathrm{Mo}$ \\
\hline \multirow{3}{*}{ 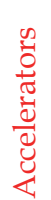 } & Photo-fission of $238 \mathrm{U}$ & Photon $+238 \mathrm{U} \rightarrow{ }^{99} \mathrm{Mo}+\mathrm{xn}+$ other fission products \\
\hline & ${ }^{100}$ Mo transmutation & Photon $+{ }^{100} \mathrm{Mo} \rightarrow{ }^{99} \mathrm{Mo}+\mathrm{n}$ \\
\hline & Direct ${ }^{99 m T c}$ production & $\mathrm{P}+{ }^{100} \mathrm{Mo} \rightarrow{ }^{99} \mathrm{mTc}+2 \mathrm{n}$ \\
\hline
\end{tabular}

Table 3. The various technological options for the production of $99 \mathrm{mTc} /{ }^{99} \mathrm{Mo}$

The usual production of ${ }^{99} \mathrm{Mo}$ for nuclear medicine depends on:

1. The neutron induced fission of $235 \mathrm{U}$, which results in expensive but high specific activity ${ }^{99} \mathrm{Mo}$ (IAEA-TECDOC-1065, 1999), or

2. The $(n, \gamma)$ nuclear reaction with ${ }^{98} \mathrm{Mo}, 24 \%$ using natural Molybdenum, resulting in inexpensive but low-specific activity ${ }^{99} \mathrm{Mo}$.

Thus, for either method, at least one neutron is required for the reaction.

Neutrons can be produced from accelerator reactions where the charged particles strike heavy atoms, also from alpha or gamma reactions with light atoms, such as beryllium or lithium. However, to produce the large quantities of neutrons needed for production of useful quantities of ${ }^{99} \mathrm{Mo}$, the most effective source is a critical nuclear reactor operating at powers in the range of megawatts. Each fission process of an atom of $235 \mathrm{U}$ produces an average of about 2.5 neutrons. In an operating reactor, these neutrons either are absorbed by materials in the reactor or escape from the boundaries of the reactor. One neutron must cause fission in another ${ }^{235} \mathrm{U}$ atom. Of the remaining 1.5 neutrons from each fission process in a critical reactor, some small fractions are available for production. The most appropriate target material for low specific activity ${ }^{99}$ Mo production is molybdenum trioxide $\left(\mathrm{MoO}_{3}\right)$; neutron activation occurs via the reaction ${ }^{98} \mathrm{Mo}(\mathrm{n}, \gamma){ }^{99} \mathrm{Mo}$.

The potential use of accelerators for these purposes is another issue of current scientific and technological interest. Recently, a matter of concern has been the availability and supply of ${ }^{99} \mathrm{Mo}$ for the manufacturing of generators. These concerns arose from several factors including, amongst others, the shutdown of some nuclear reactors, uncertainty of reliable operating condition for radioisotope production and easy availability of enriched ${ }^{235} \mathrm{U}$ target materials.

More recently, the utilization of charged particle accelerators, either LINAC's or cyclotrons, has been discussed as a potential alternative technology to the fission route. These discussions have been prompted by basic research concerns as well as the need to explore 
new production routes to offset the perceived situation of future problems with the availability of ${ }^{99} \mathrm{Mo}$ if no new dedicated reactors are licensed.

The production of ${ }^{99} \mathrm{Mo}$ via the ${ }^{100 \mathrm{Mo}}(\mathrm{p}, \mathrm{pn})$ reaction was evaluated. A good agreement was found among the different excitation functions available. However, because of the rather low cross-section values found in these measurements, the production of ${ }^{99} \mathrm{Mo}$ via this potential process was found to be largely impractical. A significant limiting factor of this approach appears to be the need for a large inventory (tens of $\mathrm{kg}$ quantities) of enriched

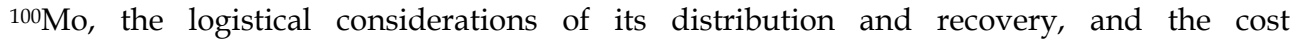
(2 US $\$ / \mathrm{mg}$ ). Furthermore, proton accelerators delivering $\mathrm{mA}$ beam on target would be required including the development of high power targets.

The production of $99 \mathrm{mTc}$ via the ${ }^{100} \mathrm{Mo}(\mathrm{p}, 2 \mathrm{n})$ reaction was also evaluated, and the cross section data available were found to be consistent and in good agreement. Extrapolating 99mTc yields obtained from this data, using the operational conditions of the existing $30 \mathrm{MeV}$ accelerator technologies, suggest that large-scale $(\mathrm{kCi})$ production of $99 \mathrm{mTc}$ is possible (Glenn, et al., 1997).

\subsection{Nuclear data needs}

The excitation function measurements of charged particle induced reactions are needed to improve and study the ideal way for medical radioisotope production. The optimization of nuclear reaction for the production of radioisotope at a cyclotron involves a selection of the projectile energy range that will maximize the yield of the product and minimize that of radionuclide impurities. The IAEA Coordinated Research program (CRP) which deals with all aspects of the production of medical radioisotopes that can be used for diagnostic and therapeutic purposes, requires a reliable database for production cross sections, not only for the main and the monitor reactions but also for the associated producing impurity reactions (IAEA-TECDOC-468, 2009). The program includes targetry (preparation, cooling and chemistry), yields, radionuclidic impurities, radiation dose from targets and target backings.

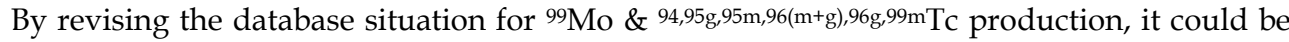
seen that the status of the present information is still not satisfactory for a detailed optimization of the production processes. Several authors (Kormali, et al., 1976; Takács, et al., 2002; Bonardi, et al., 2002; Uddin, et al., 2004; Khandaker, et al., 2006; Khandaker, et al., 2007; Uddin, et al., 2008) have reported a variety data for proton-induced reaction crosssections on molybdenum in the medium-energy range, but large discrepancies can be found among them. These discrepancies limit the reliability of data evaluations.

\section{Experimental techniques}

The reaction cross-section of the proton-induced reactions on molybdenum were measured, in this work, as a function of proton energy in the range from the respective threshold for each contributing reaction $\left(\mathrm{E}_{\mathrm{thr}}\right)$ to about $40 \mathrm{MeV}$ using the activation method and the wellestablished stacked foil technique combined with high resolution gamma-ray spectroscopy.

\subsection{Stacked foil technique}

By this method a series of thin target foils are put together to form the target as in Figure 1. Each target foil (Mo in this study) is followed by another material (mainly $\mathrm{Al}$ in our case) to 
catch the ejected product nuclides (recoils) from the preceding Mo foil. This catcher foil is selected so that it does not produce any radioactive product by the given bombarding particle at the energy range used. The catchers should be also as low Z- material as possible to decrease the gamma attenuation during the activity measurements. Therefore, a pair of foils (Mo+Al catcher) will contain the total produced radioactive isotopes from the given Mo foil after the irradiation. The catcher $\mathrm{Al}$ foil contains only the ejected atoms (radionuclides) from the Mo implanted into it. The advantage of the stacked foil method is that one can get a whole excitation function curve using a lower number of irradiations. Another advantage of this method is that each target of the stack is irradiated with the same integrated beam charge. The main conceptual disadvantage of the staked foil technique is concerned with the energy straggling that is induced in the beam by passing through the stack of thin foils, recoil catchers and energy degraders (Zeigler, J.F., 1995). The inaccuracy of the foil thickness and surface roughness, which cause the accumulation of the error in energy calculations from the first to the last foil of the stack, which can be corrected by inserting some beam current monitor foils in different regions over the stack.

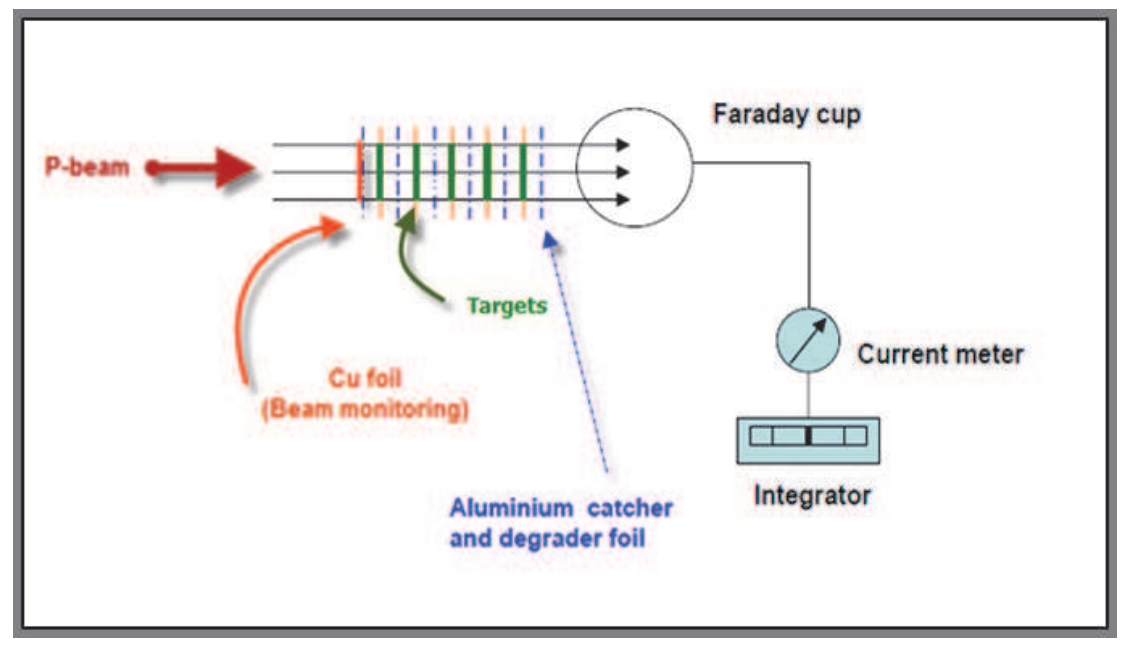

Fig. 1. Schematic diagram of the stacked foil arrangements

\subsection{Target holder and experimental setup}

An aluminum target holder (12 mm aperture) was designed as shown in Figure 2. It also acts as a Faraday cup equipped with secondary electron suppressor by applying -300 Volts to an electrically isolated cylinder attached to the target holder. An earthed collimator ring (10 mm diameter) was placed in front of the holder facing the beam. This target holder was attached to a reaction chamber shown in Figure 3, which adapted for the activation purpose. The total charges collected by the Faraday cup have been integrated using current integrator circuit with good linearity at low current values. The target foils of $10 \mathrm{~mm}$ diameter were sufficiently larger than the proton beam diameter. Care was taken to ensure that equal areas of the monitor and the target foils intercepted the beam. The irradiation geometry used guaranteed that practically the whole beam passed through every foil. The secondary effect 
of the interactions of the secondary produce neutrons with the molybdenum targets was checked by placing some foils in the end of the stack far behind the range of the fully stopped proton beam followed by the measurement of its activities.

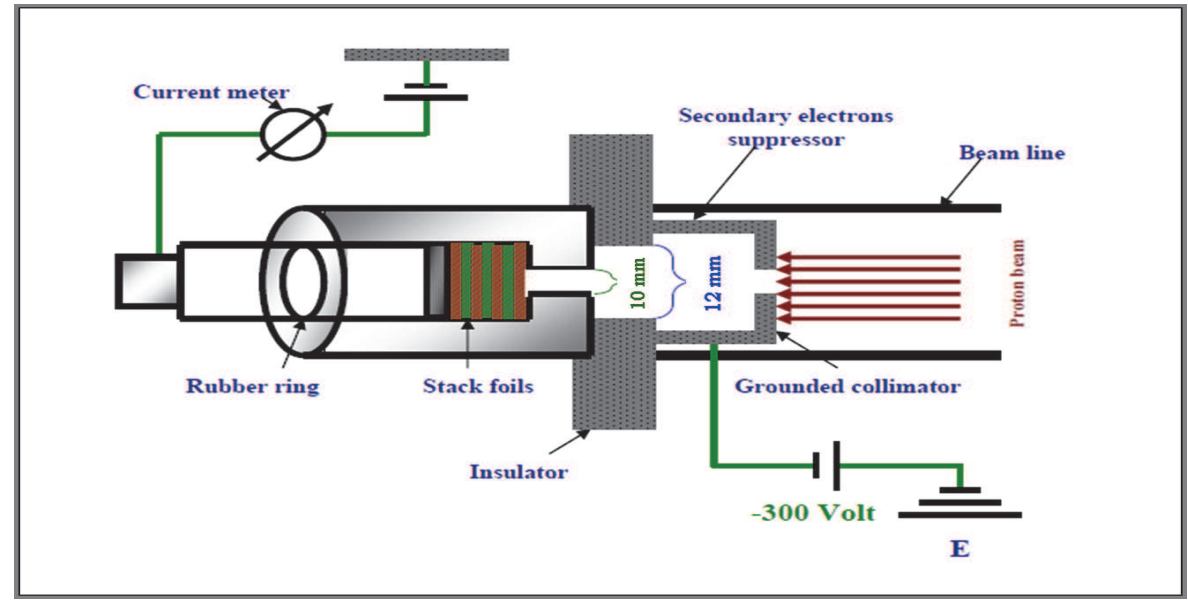

Fig. 2. Schematic diagram of the target holder and the Faraday cup

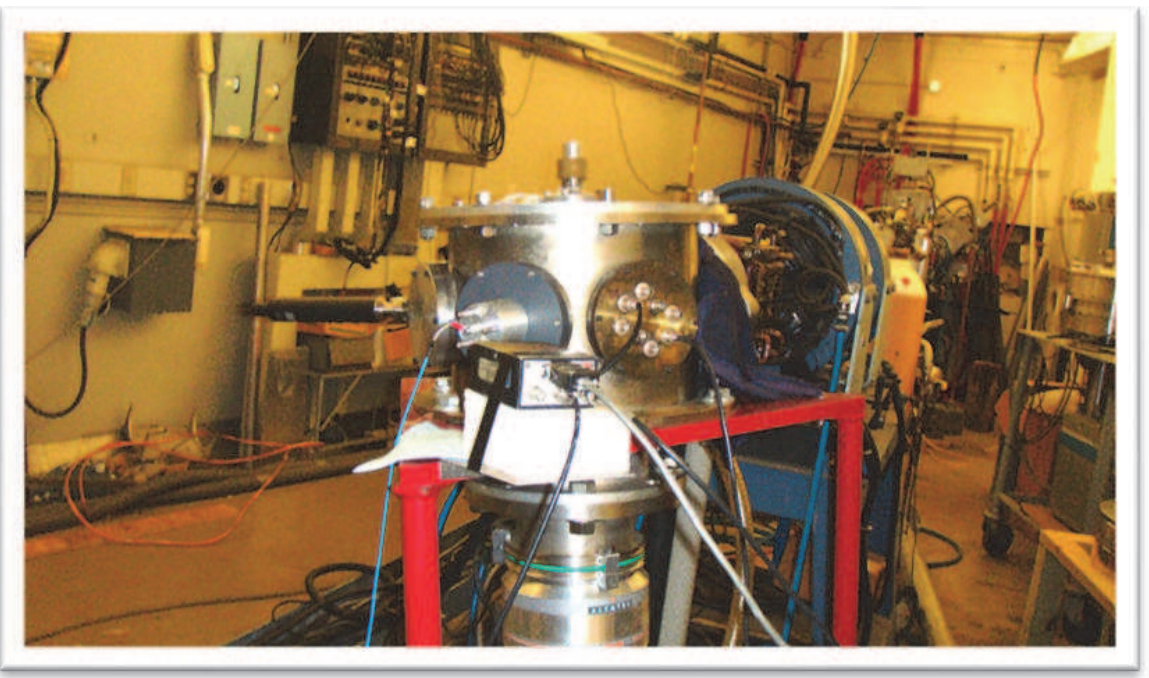

Fig. 3. A photograph of the experimental setup

\subsection{Targets and irradiations}

Thin foils of molybdenum with natural isotopic composition were used as our main targets. There are 35 known isotopes of molybdenum ranging in atomic mass from 83 to 117, as well 
as four metastable nuclear isomers. The seven stable isotopes are listed in Table 2 (Audi, et al., 2003). All unstable isotopes of molybdenum decay into isotopes of niobium, technetium, and ruthenium.

\begin{tabular}{|cc}
\hline Isotope & Natural abundance $(\%)$ \\
\hline${ }^{92 \mathrm{Mo}}$ & 14.84 \\
\hline${ }^{94} \mathrm{Mo}$ & 9.25 \\
\hline${ }^{95} \mathrm{Mo}$ & 15.92 \\
$96 \mathrm{Mo}$ & 16.68 \\
$97 \mathrm{Mo}$ & 9.55 \\
${ }^{98} \mathrm{Mo}$ & 24.13 \\
\hline${ }^{100} \mathrm{Mo}$ & 9.63 \\
\hline
\end{tabular}

Table 4. Most stable radioisotopes of molybdenum

The irradiations were performed using an external beam of accelerated protons with energy of about $40 \mathrm{MeV}$ provided by $\mathrm{K} 500$ superconducting cyclotron at Texas A\&M University, Cyclotron institute, USA. Two different sets of stacks were irradiated to cover the energy range from the respective threshold for each reaction up to $40 \mathrm{MeV}$. Each stack was made of several groups of targets; natMo (99.999\% and $50 \mu \mathrm{m}$ thickness) as the main target foils, nat $\mathrm{Cu}$ (99.98\% and $125 \mu \mathrm{m}$ thickness) were used as monitor foils that acted also as beam degraders and nat $\mathrm{Al}$ (99.999\% and 50,100 $\mu \mathrm{m}$ thickness) as catcher foils, all foils were supplied by Goodfellow, Cambridge, UK. The set of foils was pressed together to avoid air gaps between them, which could have influence on the vacuum and particles stopping. The proton energy degradation along the stack was determined using the computer program SRIM-2003 assuming the incident energy was $40 \mathrm{MeV}$ (Ziegler, et al., 1985). The irradiation conditions for each stack are shown in Table 5.

\begin{tabular}{ccccc}
\hline $\begin{array}{c}\text { Stack } \\
\text { number }\end{array}$ & $\begin{array}{c}\text { Incident energy } \\
(\mathrm{MeV})\end{array}$ & $\begin{array}{c}\text { Energy range } \\
(\mathrm{MeV})\end{array}$ & $\begin{array}{c}\text { Irradiation time } \\
\text { (hour) }\end{array}$ & $\begin{array}{c}\text { Beam current } \\
(\mathrm{nA})\end{array}$ \\
\hline Stack 1 & $39.4 \pm 0.4$ & $39.4-19$ & $30 \mathrm{~min}$ & 27 \\
Stack 2 & $20.3 \pm 0.8$ & $20.3-0$ & $50 \mathrm{~min}$ & 24 \\
\hline
\end{tabular}

Table 5. Irradiation conditions in the experiments relevant to cross-section measurements

\subsection{Monitor reactions}

To confirm the cyclotron beam intensity and energy, a thin copper monitor foil ( $50 \mu \mathrm{m})$ was placed in the front of the stack (Al-Saleh, et al., 2006). Copper is an ideal target material with respect to its availability, physical, mechanical and chemical properties to be used in monitoring process. This $\mathrm{Cu}$ foil was irradiated simultaneously with the main target foils 
and then analyzed with the same gamma ray spectrometer in a comparable geometry. Thus, the ratio $\left(a_{\text {exp }}\right)$ between the measured cross section values for the ${ }^{63} \mathrm{Cu}(\mathrm{p}, \mathrm{n}){ }^{63} \mathrm{Zn}$ and

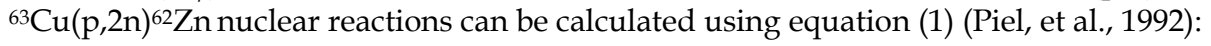

$$
\alpha_{\exp }=\frac{\sigma_{62_{Z n}}}{\sigma_{63_{Z n}}}=\frac{A_{62}\left(1-e^{-t_{b} \lambda_{63}}\right)}{A_{63}\left(1-e^{-t_{b} \lambda_{62}}\right)}
$$

where, $t_{b}$ is the irradiation time, $A_{62}$ and $A_{63}$ are the measured decay activities for both ${ }^{62} \mathrm{Zn}$ and ${ }^{63} \mathrm{Zn}$, respectively. By comparing the determined ratio which found to be $(0.0118)$ with the ratios obtained from the recommended cross-section values by the IAEA (Tárkányi, et al., 2001) and plotted, in dotted line, as a function of the proton energy in Figure 4. The energy value of the accelerated protons was estimated to be $E_{p}=39.4 \pm 0.4 \mathrm{MeV}$.

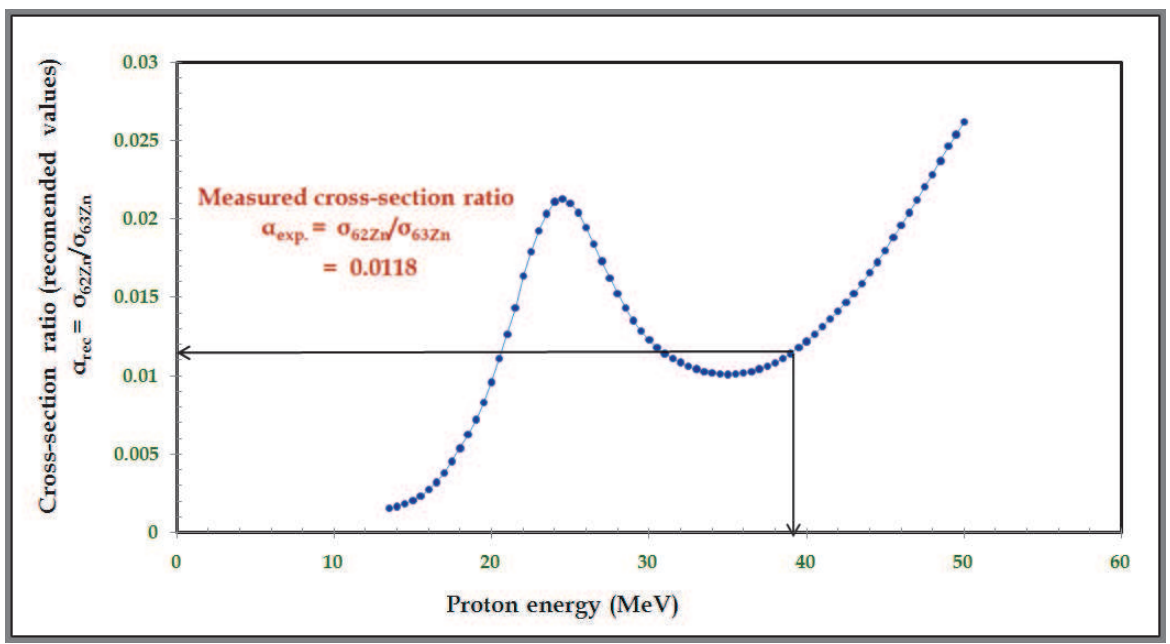

Fig. 4. The energy calibration for the Proton beam using the $\alpha_{\exp }$ ratio for $\sigma_{62 \mathrm{Zn}}$ and $\sigma_{63 \mathrm{Zn}}$

The measured $\mathrm{Cu}$ monitoring reactions were also used for beam intensity calculations, using the reverse relation to the well-known reaction cross section values. The charge collected in the Faraday cup was registered, from which the average beam current was deduced. The two results generally agreed within $10 \%$. The uncertainty of the proton energy along the stack was checked by inserting $\mathrm{Al}$ and $\mathrm{Cu}$ monitor foils into different points of the stack then by comparing the measured excitation functions for nat $\mathrm{Al}(\mathrm{p}, \mathrm{x})^{22,24} \mathrm{Na}$ and

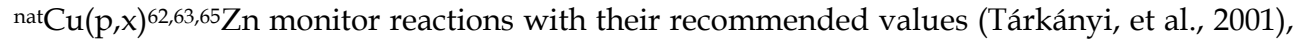
as shown in Figure 5. The individual uncertainties of the contributing reactions were taken into account considering the cumulative effects. The total uncertainty for each energy point depends on the irradiation circumstances and the position of each foil in the stack. These are the uncertainties of the target homogeneity and thickness, the incident beam energy and the beam straggling. Typical uncertainty in the energy was $( \pm 0.3 \mathrm{MeV})$ at the beginning of the stack and $( \pm 1.2 \mathrm{MeV})$ at the end. Furthermore, the very good agreement with the recommended values for the measured cross-sections of the studied monitoring reactions confirms the reliability of our experimental setup. 


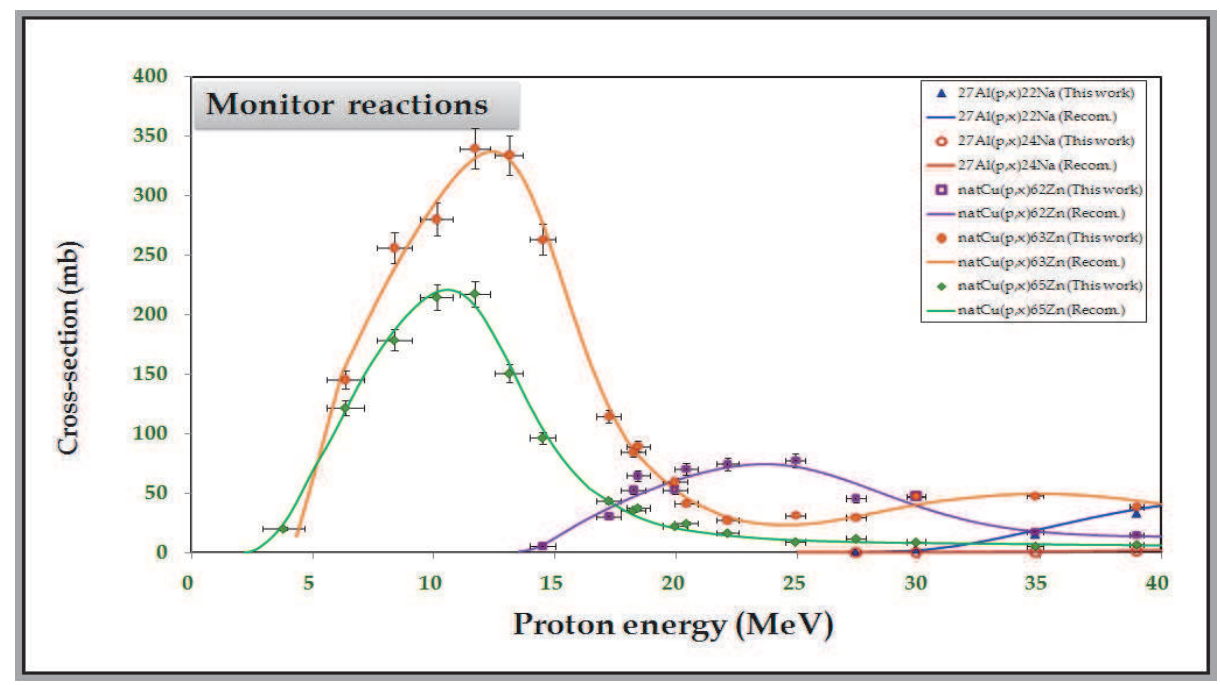

Fig. 5. Excitation functions of the monitor reactions compared with the recommended crosssections by the IAEA.

\subsection{Radioactivity measurements}

The radioactivity of the residual nuclei in the activated foils was measured nondestructively using a HPGe $\gamma$-ray detector with 70\% efficiency relative to a (3"x3") NaI detector, and energy resolution of $2.2 \mathrm{keV}$ for the $1.332 \mathrm{MeV} \gamma$-line of the ${ }^{60} \mathrm{Co}$ standard source, a peak to Compton ratio of 58: 1 . The detector absolute efficiencies for various source-detector distances and photon energies were determined experimentally by using a selected set of $\gamma$ ray standard sources $\left({ }^{60} \mathrm{Co},{ }^{137} \mathrm{Cs},{ }^{133} \mathrm{Ba}\right.$ and $\left.{ }^{152} \mathrm{Eu}\right)$, of known activities, to cover the whole energy range of the studied $\gamma$-rays. The detector-sample distance was kept large enough to ensure the point source geometry and to keep the dead time within $8 \%$ or less. In addition to the main characteristic $\gamma$-lines for each studied radioisotope, some other weaker $\gamma$-lines were also considered to minimize the relative errors due to counting statistics, wherever possible. In the cases of the longer-lived radionuclides, activity measurements were carried out after sufficient cooling time, which is enough for the complete decay of most of the undesired short-lived isotopes, to avoid any possible interference of nearly equal energies $\gamma$-lines. The stack was dismantled and each foil was counted 2-3 times after different cooling times following the end of bombardment EOB to avoid disturbance by overlapping $\gamma$-lines from undesired sources and to evaluate accurately the cross-sections for cumulative formation of the corresponding longer-lived daughter radionuclide.

Figure 6 presents an example of the calibrated measured $\gamma$-ray spectrum with identified $\gamma$ lines covering the energy range up to $1350 \mathrm{keV}$. Table 6 shows the contributing reactions and the decay data of all the investigated radionuclides, which were taken from the Table of Isotopes (Firestone, 1998 and T-16, Nuclear Physics Group, LANL 1997). 


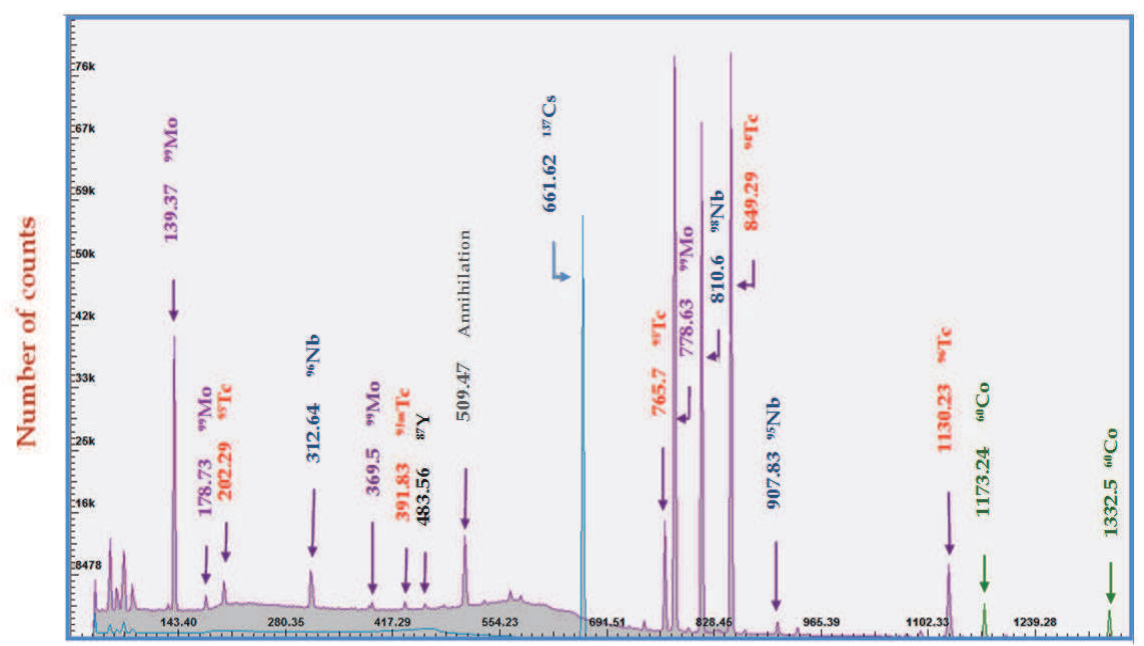

Energy (keV)

Fig. 6. A calibrated Gamma ray spectrum with identified $\gamma$-lines

\begin{tabular}{|c|c|c|c|c|c|c|}
\hline Nuclide & $\begin{array}{l}\text { Half } \\
\text { life }\end{array}$ & $\begin{array}{l}\text { Principal } \\
\text { contributing } \\
\text { reactions }\end{array}$ & $\begin{array}{c}\text { Q-value } \\
\text { MeV }\end{array}$ & Decay mode & $\begin{array}{c}\mathrm{E}_{\mathrm{Y}} \\
\mathrm{keV}\end{array}$ & IY \% \\
\hline${ }^{99}$ Mo & $2.75 \mathrm{~d}$ & $\begin{array}{l}{ }^{100} \mathrm{Mo}(\mathrm{p}, \mathrm{pn}) \\
{ }^{99} \mathrm{Nb} \rightarrow \text { decay }\end{array}$ & $\begin{array}{l}-8.30 \\
-11.14\end{array}$ & $\beta-(100)$ & $\begin{array}{l}140.51 \\
181.07 \\
739.5\end{array}$ & $\begin{array}{l}89.43 \\
5.99 \\
12.13\end{array}$ \\
\hline 94gTc & $4.88 \mathrm{~h}$ & $\begin{array}{l}{ }^{94} \mathrm{Mo}(\mathrm{p}, \mathrm{n}) \\
{ }^{95} \mathrm{Mo}(\mathrm{p}, 2 \mathrm{n}) \\
{ }^{96} \mathrm{Mo}(\mathrm{p}, 3 \mathrm{n})\end{array}$ & $\begin{array}{l}-5.03 \\
-12.41 \\
-21.56\end{array}$ & $\begin{array}{l}\mathrm{EC}(87.94 \%) \\
\beta^{+}(11.71 \%)\end{array}$ & $\begin{array}{l}702.63 \\
849.92 \\
871.08\end{array}$ & $\begin{array}{l}99.6 \\
95.7 \\
100\end{array}$ \\
\hline 95gTc & $20 \mathrm{~h}$ & 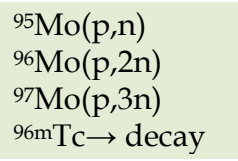 & $\begin{array}{l}-02.47 \\
-11.63 \\
-18.45\end{array}$ & EC $(100 \%)$ & $\begin{array}{l}765.79 \\
947.67 \\
1073.71\end{array}$ & $\begin{array}{l}93.82 \\
01.95 \\
03.74\end{array}$ \\
\hline 96gTc & $4.28 \mathrm{~d}$ & $\begin{array}{l}{ }^{96} \mathrm{Mo}(\mathrm{p}, \mathrm{n}) \\
{ }^{97} \mathrm{Mo}(\mathrm{p}, 2 \mathrm{n}) \\
{ }^{98} \mathrm{Mo}(\mathrm{p}, 3 \mathrm{n})\end{array}$ & $\begin{array}{l}-03.76 \\
-10.58 \\
-19.22\end{array}$ & EC $(100 \%)$ & $\begin{array}{l}778.22 \\
812.58 \\
849.92\end{array}$ & $\begin{array}{l}99.76 \\
82.0 \\
98.0\end{array}$ \\
\hline $96 \mathrm{mTc}$ & $\begin{array}{l}51.50 \\
\min \end{array}$ & $\begin{array}{l}{ }^{96} \mathrm{Mo}(\mathrm{p}, \mathrm{n}) \\
{ }^{97} \mathrm{Mo}(\mathrm{p}, 2 \mathrm{n}) \\
{ }^{98} \mathrm{Mo}(\mathrm{p}, 3 \mathrm{n})\end{array}$ & $\begin{array}{l}-03.76 \\
-10.58 \\
-19.22\end{array}$ & IT (98\%) & $\begin{array}{l}34.28 \\
778.22 \\
1200\end{array}$ & $\begin{array}{l}100.0 \\
01.90 \\
01.08\end{array}$ \\
\hline 99mTc & $6.01 \mathrm{~h}$ & $\begin{array}{l}{ }^{100} \mathrm{Mo}(\mathrm{p}, 2 \mathrm{n}) \\
{ }^{99} \mathrm{Mo} \rightarrow \text { decay }\end{array}$ & -7.60 & $\mathrm{IT}+\beta-(100)$ & 140.51 & 89.06 \\
\hline
\end{tabular}

Table 6 . The contributing reactions and the decay data of the investigated radioisotopes 


\subsubsection{Separation of interfered $y$-lines}

Some investigated radionuclides emit $\gamma$-rays that have very close energies, which were difficult to be separated using the HPGe spectrometer.

The individual activities of those overlapped $\gamma$-rays were analyzed using the difference in half-lives of the contributing nuclides by plotting the $\gamma$-ray emission rate as a function of time. Figure 7 shows the radioactive decay curve for the $140.5 \mathrm{keV} \mathrm{\gamma}$-peak which resulted from the decay of the directly produced ${ }^{99} \mathrm{Mo}(65.94 \mathrm{~h}, 140.51 \mathrm{keV})$, the directly and indirectly produced $99 \mathrm{mTc}(6.01 \mathrm{~h}, 140.51 \mathrm{keV})$, and ${ }^{90} \mathrm{Nb}(14.6 \mathrm{~h}, 141.2 \mathrm{keV})$. The radionuclides decay completely in the order of their half-lives, ${ }^{99}$ Mo the longest-lived nuclide is the last to decay. After more than 14 days, the remaining activity was due to decay of the daughter nuclide $99 \mathrm{mTc}$ in transient equilibrium with the parent ${ }^{99} \mathrm{Mo}$ radionuclide. The activities of the radionuclide; ${ }^{99} \mathrm{Mo}\left(A_{2}\right) \rightarrow{ }^{99 \mathrm{mTc}}\left(A_{1}\right)$ at the end of bombardment (EOB) were estimated by using equation (2) (Uddin, et al., 2004):

$$
A_{1(E O B)}=\frac{A_{1+2}\left(\lambda_{2}-\lambda_{1}\right)}{\exp \left(-\lambda_{1} t_{c}\right)+\lambda_{2}\left[\exp \left(-\lambda_{1} t_{c}\right)-\exp \left(-\lambda_{2} t_{c}\right)\right]}
$$

where $t_{c}$ is the respective cooling time, $\lambda_{1}$ and $\lambda_{2}$ are the decay constants of ${ }^{99} \mathrm{Mo}$ and ${ }^{99 \mathrm{mTc}}$, respectively, and $A_{1(E O B)}$ is the activity of ${ }^{99} \mathrm{Mo}$ at the EOB. To separate the activities after the EOB of ${ }^{90} \mathrm{Nb}\left(A_{3(E O B)}\right)$ and ${ }^{99} \mathrm{mTc}\left(A_{4(E O B)}\right)$, we used the following equation (3):

$$
A_{3+4}=A_{3(E O B)} \exp \left(-\lambda_{3} t_{c}\right)+A_{4(E O B)} \exp \left(-\lambda_{4} t_{c}\right)
$$

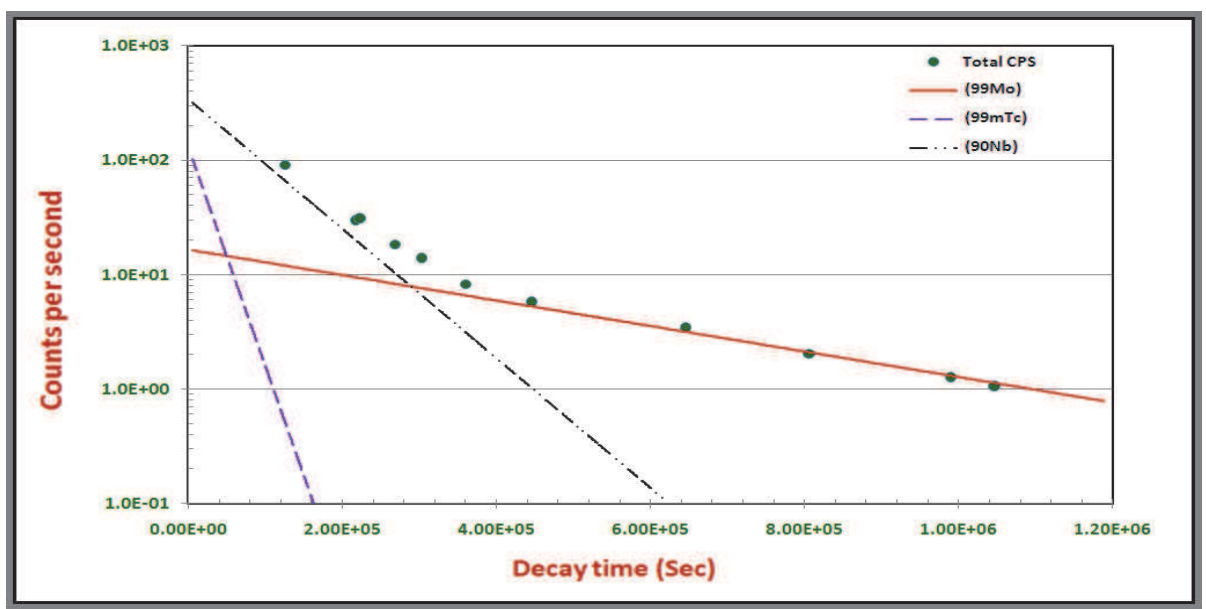

Fig. 7. Resolving the $140 \mathrm{keV} \gamma$-line which produced from three different radioisotopes ${ }^{99} \mathrm{Mo}$, $99 \mathrm{mTc}$ and ${ }^{90 \mathrm{Nb}}$

The daughter $99 \mathrm{mTc}$ activity decreases from the maximum at a constant rate, which depends on the decay rate of ${ }^{99} \mathrm{M}$. Then the directly produced ${ }^{99 \mathrm{~m} T c}$ completely decayed out before the measurement. The measured activity for the $140.5 \mathrm{keV} \gamma$-line was the sum of the $\gamma$-line from the daughter ${ }^{99} \mathrm{mTc}$ and from ${ }^{90} \mathrm{Nb}$. We deduced the activities of 140.5 
and $141.2 \mathrm{keV} \gamma$-lines from the independent $\gamma$-lines of ${ }^{99} \mathrm{Mo}$ and ${ }^{90} \mathrm{Nb}$, respectively; an excellent agreement was obtained when compared with the results of radioactive decay curve.

\subsection{Cross section calculations and uncertainty}

The reaction cross sections for the nuclear reactions nat $\mathrm{Mo}(\mathrm{p}, \mathrm{x})$ were calculated using the activation formula as in equation 4 considering the decay data and rates of the radioactive isotopes produced, the detector absolute efficiency, and the measured beam intensity (Helus \& Colombetti, 1980).

$$
\bar{\sigma}=\frac{M Z e \lambda T_{\gamma}}{I_{\gamma} \Delta x N_{A} f \rho I \varepsilon_{a b s}\left(1-e^{-\lambda t_{b}}\right) e^{-\lambda t_{c}}\left(1-e^{-\lambda t_{m}}\right)}
$$

Whereas; $M$ is the target molecular weight, $Z e$ is the projectile charge, $\lambda$ is the decay constant, $T_{\gamma}$ is the net area under each $\gamma$-peak, $I_{\gamma}$ is the gamma line intensity, $\Delta \mathrm{x}$ is the thickness of each target foil, $N_{A}$ is the Avogadro's number, $f$ is the abundance of the isotope, $\rho$ is the target density, $I$ is the beam intensity, $\varepsilon_{a b s}$ is the detector efficiency corresponding to each $\gamma$-line energy, $t_{c}$ is the cooling time and $t_{m}$ is the measuring time.

The total experimental error was calculated by combining the individual errors as a square root of the sum of squares of the contributing relative errors, which are the lack of precision in: measuring the absolute detector efficiency of $3-6 \%$, the calculation of the area under the photoelectric peak $1-4 \%$, measuring the current intensity $4-7 \%$, the calculation of irradiation time $2 \%$, determining the foil thicknesses and composition $1-4 \%$ and the nuclear decay data of $3 \%$. The total experimental errors were obtained to be $(8-12 \%)$. The total uncertainty in each energy point depends on the irradiation circumstances and the position of the foil in the stack.

\section{Nuclear model calculations}

All the measured cross sections over the whole energy range were simulated using TALYS (Koning, et al., 2008) code. A short description for the codes is given in the following:

\subsection{TALYS code}

We calculated the independent formation cross sections for both the ground and/or the isomeric states by using the TALYS code, which is a computer program that integrates all types of nuclear reactions in the energy range of $1 \mathrm{keV}-200 \mathrm{MeV}$. TALYS incorporates modern nuclear models for the optical model, level densities, direct reactions, compound reactions, pre-equilibrium reactions, fission reactions, and a large nuclear structure database (Koning, et al., 2008). The database of this code is derived from the (Reference Input Parameter Library, http://www-nds.iaea.org/ripl2/). The pre-equilibrium particle emission is described using the two-component exciton model. The model implements new expressions for internal transition rates and new parameterization of the average squared matrix element for the residual interaction obtained using the optical model potential. The phenomenological model is used for the description of the pre-equilibrium complex particle emission. The contribution of direct processes in inelastic scattering is calculated using the 
ECIS-94 code (Raynal, 1994) incorporated in TALYS (Raynal, 1994). The equilibrium particle emission is described using the Hauser-Feshbach model. The default optical model potentials (OMP) which used in TALYS are the local and the global parameterizations for neutrons and protons. These parameters can be adjusted in some cases by the user. The present results of all the calculated excitation functions were evaluated using the default values of the code.

\section{Result and discussion}

The experimentally constructed excitation functions for the main investigated

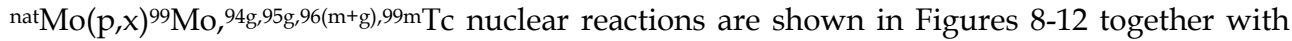
the results of the theoretical calculation using TALYS code and the previously published data. The numerical values of the present experimental cross-sections and their estimated uncertainties are presented in Table 7 .

\begin{tabular}{|c|c|c|c|c|c|}
\hline \multirow{2}{*}{$\begin{array}{c}\text { Proton } \\
\text { Energy } \\
\mathrm{MeV}\end{array}$} & \multicolumn{5}{|c|}{ Reaction Cross-section (mb) } \\
\hline & $\begin{array}{c}\text { nat } M o(p, x n)^{99} M \\
\text { o }\end{array}$ & $\begin{array}{c}\text { nat }^{M o}(p, x n)^{94 g} \\
\text { Tc }\end{array}$ & $\begin{array}{c}\text { nat } M o(p, x n)^{95 g} \\
\text { Tc }\end{array}$ & $\begin{array}{c}\left.\text { natMo(p, }^{\text {Mon }}\right)^{96(} \\
\text { m+g)Tc }\end{array}$ & $\begin{array}{c}\text { natMo(p,xn })^{99} \\
\text { mTc }\end{array}$ \\
\hline $39 \pm 0.3$ & $159 \pm 10$ & $62 \pm 6$ & $113 \pm 11$ & $73 \pm 7$ & $17 \pm 2$ \\
\hline $35 \pm 0.3$ & $166 \pm 11$ & $75 \pm 7$ & $109 \pm 11$ & $122 \pm 12$ & $22 \pm 2$ \\
\hline $30 \pm 0.4$ & $165 \pm 11$ & $77 \pm 6$ & $84 \pm 9$ & $184 \pm 11$ & $20 \pm 2$ \\
\hline $27 \pm 0.4$ & $159 \pm 10$ & $75 \pm 6$ & $90 \pm 9$ & $192 \pm 11$ & $28 \pm 2$ \\
\hline $25 \pm 0.4$ & $141 \pm 10$ & $77 \pm 7$ & $120 \pm 11$ & $173 \pm 12$ & $35 \pm 3$ \\
\hline $22 \pm 0.5$ & $122 \pm 9$ & $72 \pm 7$ & $158 \pm 12$ & $115 \pm 12$ & $84 \pm 8$ \\
\hline $20 \pm 0.5$ & $103 \pm 9$ & $69 \pm 7$ & $146 \pm 12$ & $100 \pm 10$ & $120 \pm 10$ \\
\hline $20 \pm 0.5$ & $95 \pm 9$ & $74 \pm 7$ & $140 \pm 11$ & $97 \pm 9$ & $152 \pm 11$ \\
\hline $18 \pm 0.5$ & $79 \pm 8$ & $70 \pm 7$ & $122 \pm 11$ & $100 \pm 9$ & $182 \pm 12$ \\
\hline $18 \pm 0.5$ & $71 \pm 8$ & $72 \pm 7$ & $120 \pm 11$ & $95 \pm 9$ & $202 \pm 15$ \\
\hline $17 \pm 0.6$ & $51 \pm 5$ & $73 \pm 7$ & $115 \pm 11$ & $110 \pm 9$ & $220 \pm 18$ \\
\hline $15 \pm 0.6$ & $19 \pm 10$ & $60 \pm 6$ & $120 \pm 11$ & $127 \pm 10$ & $222 \pm 16$ \\
\hline $13 \pm 0.6$ & $10 \pm 1$ & $43 \pm 4$ & $106 \pm 10$ & $153 \pm 13$ & $196 \pm 16$ \\
\hline $12 \pm 0.7$ & $4 \pm 1$ & $28 \pm 2$ & $84 \pm 8$ & $165 \pm 11$ & $170 \pm 14$ \\
\hline $10 \pm 0.7$ & $2 \pm 0.3$ & $9 \pm 0.7$ & $77 \pm 8$ & $125 \pm 10$ & $116 \pm 11$ \\
\hline $8 \pm 0.8$ & & & $66 \pm 7$ & $89 \pm 8$ & $6 \pm 0.9$ \\
\hline $6 \pm 0.9$ & & & & $53 \pm 6$ & \\
\hline
\end{tabular}

Table 7. Measured cross-sections for the proton-induced nuclear reactions on natMo. 


\subsection{Excitation functions \\ 4.1.1 ${ }^{\text {nat }}$ Mo(p,xn) ${ }^{99}$ Mo}

${ }^{99} \mathrm{Mo}$ is produced by proton activation on natMo target via the contribution of two reaction channels ${ }^{100 \mathrm{Mo}}(\mathrm{p}, \mathrm{pn})^{99} \mathrm{Mo}(\mathrm{Q}=8.3 \mathrm{MeV})$ and ${ }^{100} \mathrm{Mo}(\mathrm{p}, 2 \mathrm{p})^{99} \mathrm{Nb}(\mathrm{Q}=11.14 \mathrm{MeV})$ through the $\beta^{-}$ decay of the parent isotope ${ }^{99} \mathrm{Nb}(15 \mathrm{~s})$. The highest cross-section value of about $160 \mathrm{mb}$ corresponds to $\mathrm{E}_{\mathrm{p}}=30 \mathrm{MeV}$.

A comparison between our measured cross-sections and the previously reported data together with the theoretical calculations using TALYS code is presented in Figure 8. (Takács, et al., 2003) reported cross-section data up to $37 \mathrm{MeV}$ and (Levkovskij, 1991)

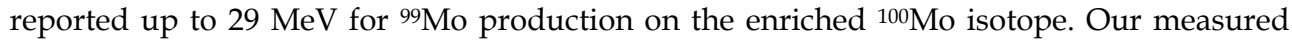
values are consistent with the data presented by (Uddin, et al., 2004). The data reported by (Scholten, et al.,1999) are consist with our data in energy range lower than $22 \mathrm{MeV}$, although his results at the higher energies are scattered. Our results showed agreement with (Takács, et al., 2003) in low energy region. The data presented by (Levkovskij, 1991) are about 25\% higher than our data. (Lagunas-solar, et al., 1991) reported numerical cross-section data that are much lower than our measured data and the other published data as well in the energy region above $20 \mathrm{MeV}$. A good agreement exists between the measured cross-sections and the TALYS code calculations within the experimental error and that fact confirms the reliability of our measured data.

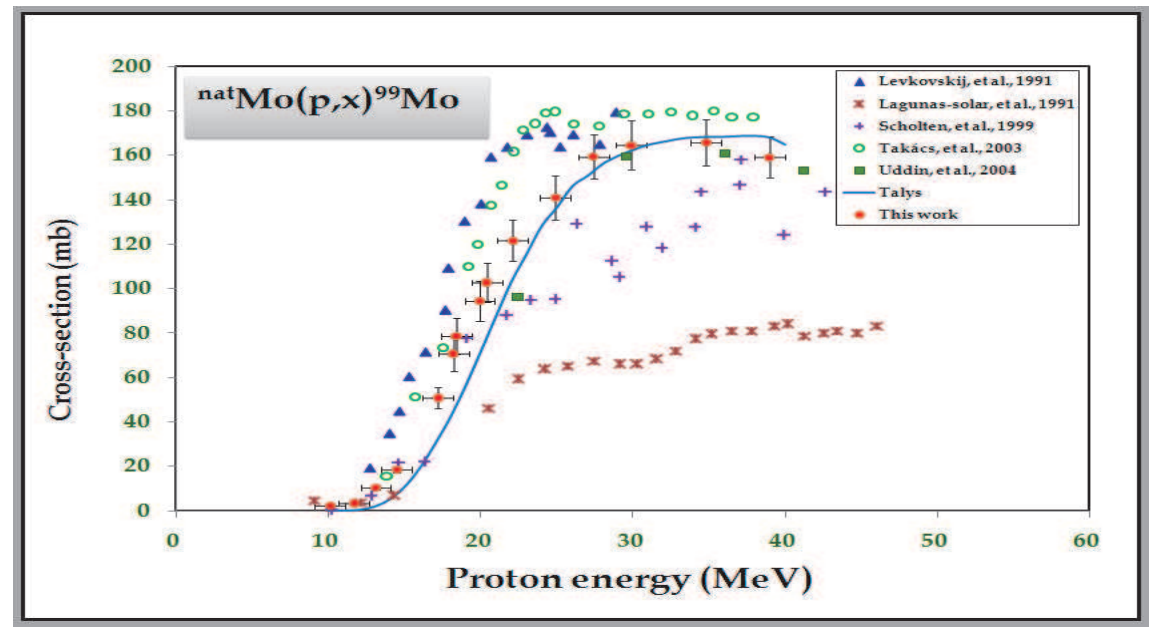

Fig. 8. Excitation function of the nat $\mathrm{Mo}(\mathrm{p}, \mathrm{x})$ reaction (full red dots with vertical and horizontal error bars) compared to some previously published results and the TALYS code calculations (curve).

\subsection{2 ${ }^{\text {nat }} \mathrm{Mo}(\mathrm{p}, \mathrm{xn})^{94 \mathrm{~g}} \mathrm{Tc}$}

${ }^{94} \mathrm{Tc}$ has two isomeric states, metastable state $94 \mathrm{mTc}\left(\mathrm{T}^{1 / 2}=52 \mathrm{~min}, 2^{+}\right)$and ground state $\left(\mathrm{T}^{1 / 2}=\right.$ $\left.4.86 \mathrm{~h}, 7^{+}\right)$. We studied the excitation function for the ground state only due to the relatively short half-life of the metastable state. The contribution of the isomeric transition (IT< 0.1$)$ for $94 \mathrm{mTc}$ is small enough to be neglected. Therefore, we can study each state separately by eliminating the interfering gamma rays from the measurements, such as $849.92 \mathrm{keV}$ and 
$871.08 \mathrm{keV}$ as listed in Table 6. Mainly we used the $702.63 \mathrm{keV} \mathrm{\gamma}$-line, which has no interference with any other $\gamma$-lines from any other produced isotopes in a cooling time of about 5 hours, to determine the cross section for ${ }^{94} \mathrm{~g} \mathrm{Tc}$ production.

The present experimental excitation function for the reaction natMo(p,xn $)^{94 \mathrm{gTc}}$ is presented in Figure 9 together with the previously published results and the calculated cross sections by the used nuclear model code TALYS.

A good agreement is found between our measured cross sections and the ones reported by (Bonardi, et al., 2002 and Uddin, et al., 2004) over the entire energy range. There is a remarkable difference between the present results and the reported data by (Khandaker, et al., 2007) especially for the energies lower than $20 \mathrm{MeV}$ and above $30 \mathrm{MeV}$. The measured cross sections by (Kormali, et al., 1976) show about $40 \%$ lower values than our data in the energy range from 11-20 MeV. The TALYS code calculation is about $50 \%$ higher than our measured data and higher than all the previously reported data sets.

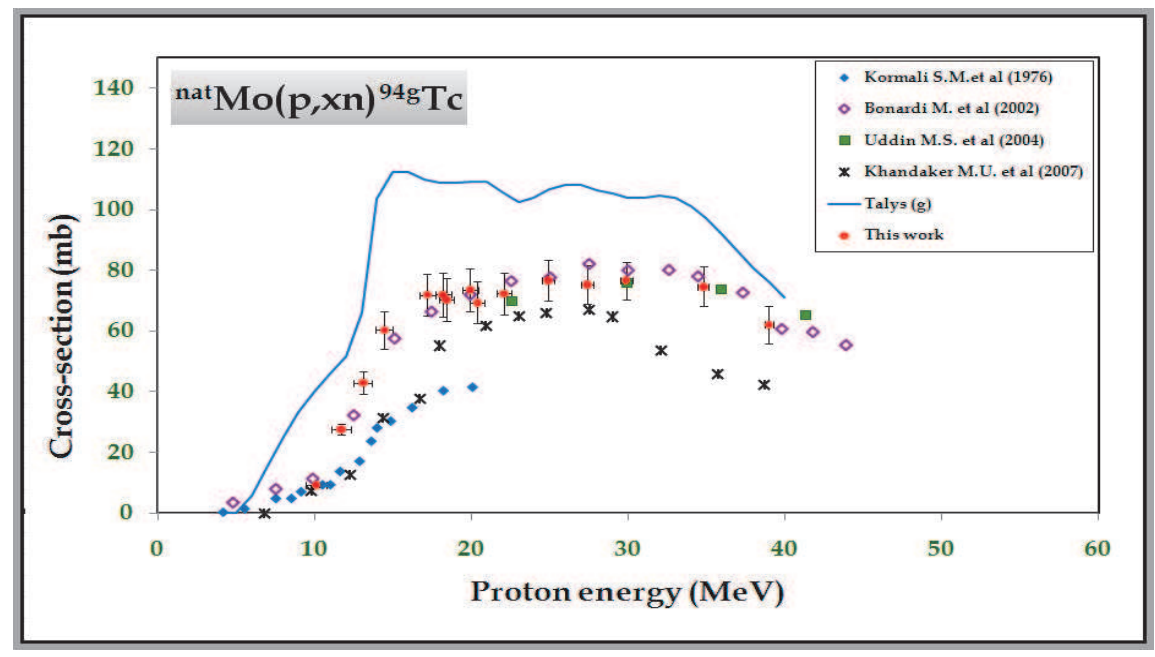

Fig. 9. Excitation function of the nat $\mathrm{Mo}(\mathrm{p}, \mathrm{x})$ reaction (full red dots) compared to some previously published results and the TALYS code calculations (curve).

\subsection{3 ${ }^{\text {nat }} \mathrm{Mo}(\mathrm{p}, \mathrm{xn})^{95 \mathrm{~g}} \mathrm{Tc}$}

95Tc is formed in two different states: the longer lived isomeric state $95 \mathrm{mTc}\left(\mathrm{T}^{1} / 2=61 \mathrm{~d}, 1 / 2^{-}\right)$ and the shorter lived ground state $95 \mathrm{gTc}\left(\mathrm{T}^{1 / 2}=20 \mathrm{~h}, 9 / 2^{+}\right)$. In this study, we report only the measured cross sections for 95gTc due to the difficulty in measuring the interfering characteristic $\gamma$-rays for $95 \mathrm{mTc}$ as shown in Table 6. The $95 \mathrm{gTc}$ activity measurement was based on detecting the main $\gamma$-line at $765.79 \mathrm{keV}$. A comparison of the present measured data with some previously reported data and the TALYS code calculations is shown in Figure 10.

The cross section is only measurable at $8 \mathrm{MeV}$, then increases gradually due to the ${ }^{95 \mathrm{Mo}}$ $(\mathrm{p}, \mathrm{n})$ reaction. The contribution of the ${ }^{96} \mathrm{Mo}(\mathrm{p}, 2 \mathrm{n})$ reaction appears as a little plateau starting at about $12 \mathrm{MeV}$, while the ${ }^{97} \mathrm{Mo}(\mathrm{p}, 3 \mathrm{n})$ reaction contribution starts at about $20 \mathrm{MeV}$, creating another small peak. There is a good agreement between our experimental excitation function 
and the previously published data by (Bonardi, et al., 2002 and Khandaker, et al., 2007) within the experimental error, while the earlier presented study by (Khandaker, et al., 2006) shows $35 \%$ higher value than our experimental data at energies above $26 \mathrm{MeV}$. However, the data reported by (Birattari, et al., 2002) shows higher cross-section values in the proton energy range $>10 \mathrm{MeV}$. The presented data by (Uddin, et al., 2004) shows inconsistency with most of the other experimental data, , especially for the point at about $22 \mathrm{MeV}$.

The TALYS code calculation results are in good consistency with our experimental data within the experimental error, but there exists a small drop in the measured cross section values in the higher values of the energy range.

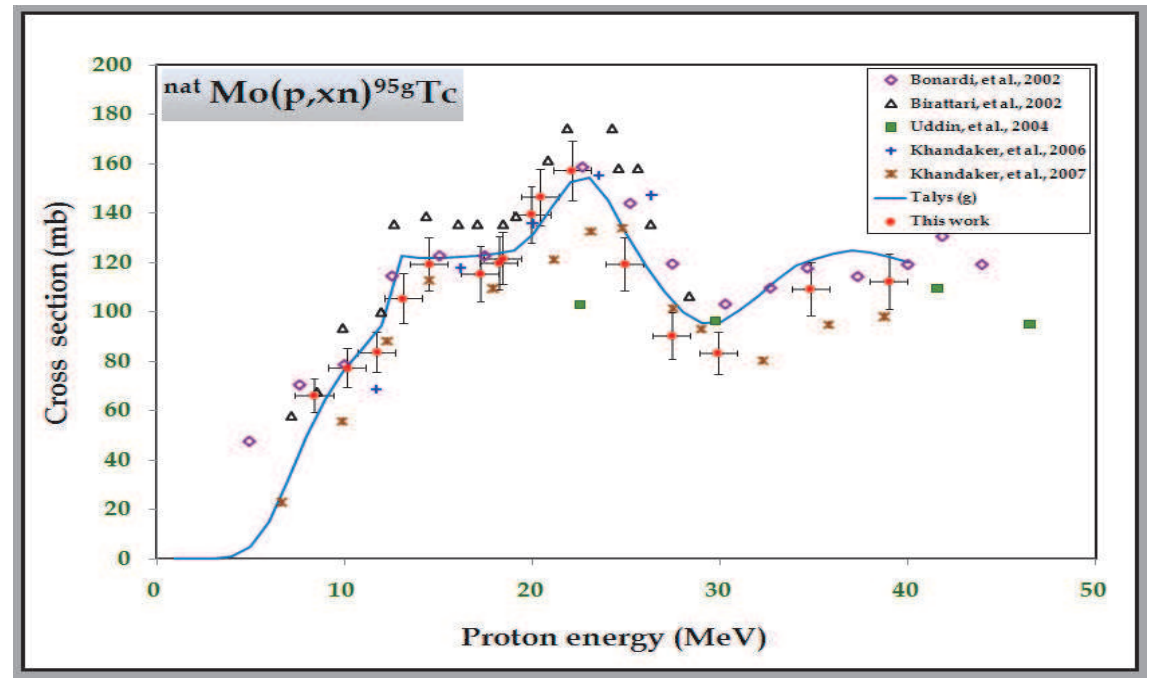

Fig. 10. Excitation function of the nat $\mathrm{Mo}(\mathrm{p}, \mathrm{x})^{95 \mathrm{~g} T \mathrm{~T}}$ reaction compared to some previously published results and the TALYS code calculations.

\subsection{4 ${ }^{\text {nat }} \mathrm{Mo}(p, x n)^{96(m+g)} \mathrm{Tc}$}

${ }^{96} \mathrm{Tc}$ is formed in two energy states: $96 \mathrm{mTc}\left(\mathrm{T}^{1 / 2}=51.5 \mathrm{~min}, 4^{+}\right)$that decays by $98 \%$ isomeric transition to the ground state $96 \mathrm{gTc}\left(\mathrm{T}^{1 / 2}=4.28 \mathrm{~d}, 7^{+}\right)$. In this study we measured the crosssection of $96 \mathrm{gTc}$ using the main characteristic $\gamma$-line $778.2 \mathrm{keV}$, while it was not possible to measure the characteristic isomeric transition $34.28 \mathrm{keV}$ of the metastable state due to the intensive interfering of the X-rays. According to the short half-life and the high IT decay rate of the metastable state, we can consider the measured cross section as the total cross section of $96(\mathrm{~m}+\mathrm{g}) \mathrm{Tc}$ without measuring the metastable state independently. Figure 11 illustrates a comparison between our measured cross sections and the available published data together with the TALYS code calculations. Some findings can be summarized from this figure as follows:

- The first part of the curve is due to ${ }^{96} \mathrm{Mo}(\mathrm{p}, \mathrm{n})$ reaction. It starts to increase rapidly to form a peak at $12 \mathrm{MeV}$. Then it decreases slowly and forms a plateau in the range 16-21 $\mathrm{MeV}$ due to the contribution of the ${ }^{97} \mathrm{Mo}(\mathrm{p}, 2 \mathrm{n})$ and ${ }^{98} \mathrm{Mo}(\mathrm{p}, 3 \mathrm{n})$ reactions which start at 
11 and $19 \mathrm{MeV}$, respectively. The rapid increase in the cross-section values at energies higher than $22 \mathrm{MeV}$ indicates the increasing contribution of the $(\mathrm{p}, 3 \mathrm{n})$ reaction.

- Very good agreement is found in the energy range above $9 \mathrm{MeV}$ between the present data and those reported by (Takács, et al., 2002; Uddin, et al., 2004 \& Khndaker, et al 2006,2007).

- The results by (Bonardi, et al., 2002) overestimate the cross-section value in the energy range $<10$ and $>26 \mathrm{MeV}$.

- The data by (Khandaker, et al., 2007) are somewhat low in the proton energy range below $10 \mathrm{MeV}$.

An overall good agreement is found between the present experimental excitation function for $96(\mathrm{~m}+\mathrm{g}) \mathrm{Tc}$ formation and the calculated theoretical results by TALYS code and the recommended data (Takács, et al., 2002), within the experimental error.

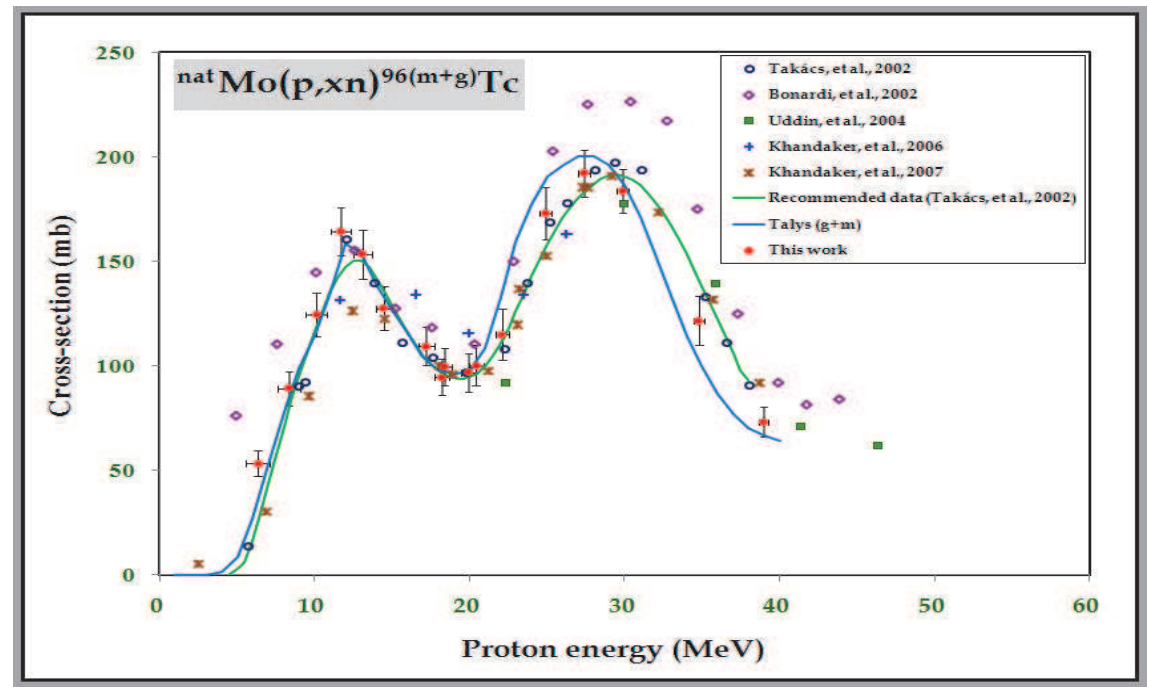

Fig. 11. Excitation function of the nat $\mathrm{Mo}(\mathrm{p}, \mathrm{x})^{96(\mathrm{~m}+\mathrm{g}) \mathrm{Tc}} \mathrm{c}$ reaction compared to some previously published results and the TALYS code calculations.

\subsection{5 ${ }^{\text {nat }} \mathrm{Mo}(\mathrm{p}, \mathrm{xn})^{99 \mathrm{~m}} \mathrm{Tc}$}

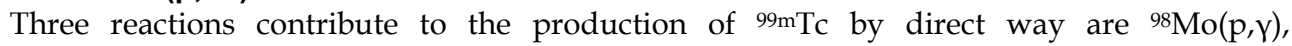
${ }^{100} \mathrm{Mo}(\mathrm{p}, 2 \mathrm{n})$, and indirect way by ${ }^{100} \mathrm{Mo}(\mathrm{p}, \mathrm{pn})$. Possibly, the highest contribution is from the ${ }^{100} \mathrm{Mo}(\mathrm{p}, 2 \mathrm{n}){ }^{99 \mathrm{~m} T c}$ reaction (on the $9.63 \%{ }^{100} \mathrm{Mo}$ present in the highly chemically pure Mo sample). Activity of $99 \mathrm{mTc}$ was measured in this work by detecting the gamma peak at energy $140.5 \mathrm{MeV}$ after the resolution of this peak as described before. The measured excitation function is compared with some earlier published data and the TALYS code calculations in Figurer 12. The data of (Takács, et al. 2003) and ( Kandaker, et al. 2007) fit nicely our measured data specially in the low energy part up to $20 \mathrm{MeV}$. At higher energies (Kandakar, et al. 2007) data clearly over estimate our results. The results of (Challan, et al. 2007) agree with our results except the last two points. The cross section data for (Scholtan, et al. 1999) are clearly lower than our values over the hall energy range. The TALYS 
calculations over estimate the present results, especially in the energy range lower than 18 $\mathrm{MeV}$, while they fit, within the experimental errors in the higher range.

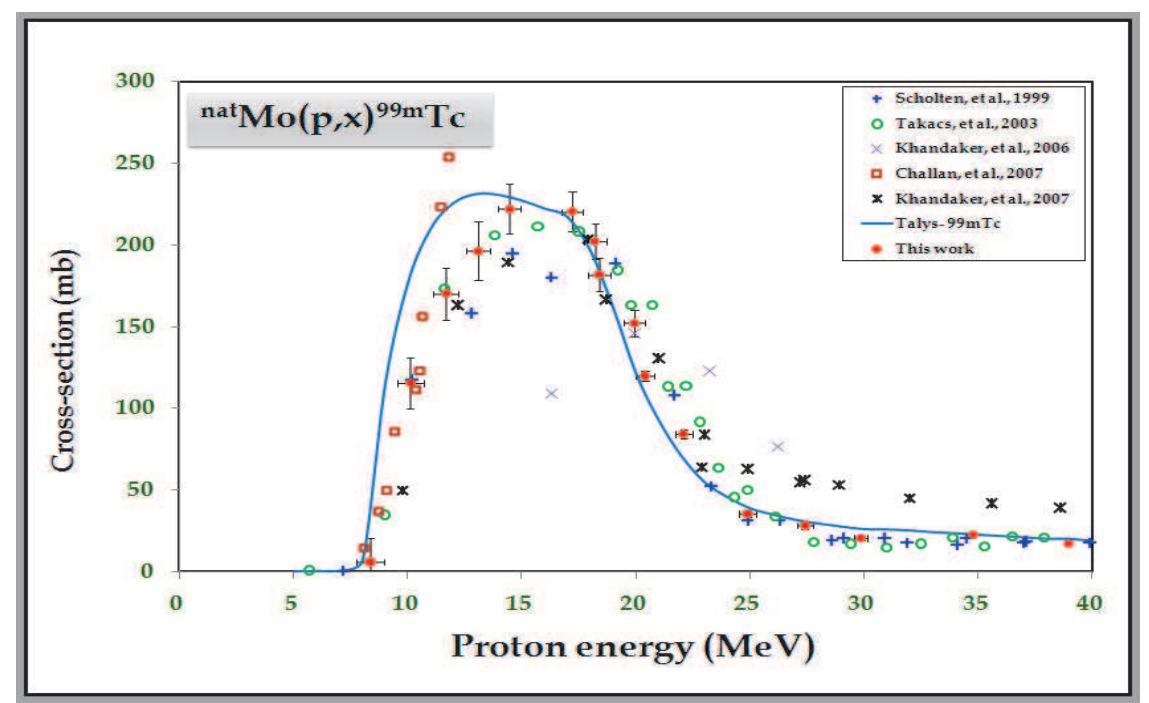

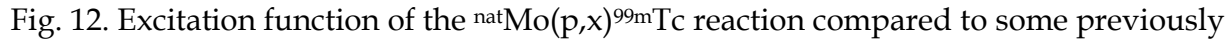
published results and the TALYS code calculations.

\subsection{Integral yield calculations}

The integral yields, at the end of bombardment, for the production of the different isotopes were derived using the measured excitation functions for the production of these radioisotopes. The method was done by assuming the thick target as dividend to several thin targets each of an equivalent thickness of about $0.5 \mathrm{MeV}$. The cross section at each thin target is assumed constant, because of the small energy interval through the target. The number of target atoms $/ \mathrm{cm}^{2}$ was calculated using the target thickness, which reduce the proton energy by $0.5 \mathrm{MeV}$. The differential yield produced in each thin target was calculated using the following equation (5):

$$
Y(E)\left(\frac{M B q}{\mu A \cdot h}\right)=N \cdot P \cdot \bar{\sigma}(E) \cdot 10^{-30} \cdot\left(1-e^{-\lambda t_{b}}\right)
$$

Whereas, $\bar{\sigma}(E)(\mathrm{mb})$ is the average cross section at a specific energy; $N$ is the number of target atoms $/ \mathrm{cm}^{2} ; \lambda$ is the decay constant for the produced isotopes; $P$ is the number of incident protons/sec for $(1 \mu \mathrm{A})$ and the irradiation time $\left(t_{b=} 1 \mathrm{~h}\right)$. We then calculated the integral target yield by summing up the differential yields.

Figure 13 represents the values of the integral target yield for the studied reactions as a function of the proton energies. Obviously, the yields of the investigated radioisotopes increase with the proton energy and start to saturate at energy of about $30 \mathrm{MeV}$. The nearly saturation values for ${ }^{99} \mathrm{Mo},{ }^{94 \mathrm{gTc}}$, ${ }^{95 \mathrm{gTc}},{ }^{96}(\mathrm{~m}+\mathrm{g}) \mathrm{Tc}$, and ${ }^{99 \mathrm{mTc}}$ are equal to 110, 600, 310, 90 and $910 \mathrm{MBq} / \mu$ A.h, respectively. 
For the production of $99 \mathrm{mTc}$ via cyclotron, it is highly recommended to use an enriched

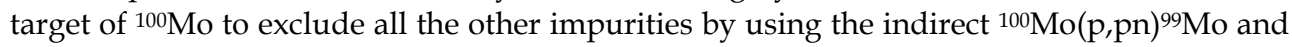
the direct ${ }^{100} \mathrm{Mo}(\mathrm{p}, 2 \mathrm{n}){ }^{99 \mathrm{mT}} \mathrm{c}$ nuclear reactions. From the present data we conclude that the optimum energy range for the production of $99 \mathrm{mTc}$ directly and indirectly using protons is $\mathrm{Ep}=35-18 \mathrm{MeV}$, the integral target yield amounting to to $412 \mathrm{MBq} / \mu \mathrm{A} . \mathrm{h}$ to $1000 \mathrm{MBq} / \mu \mathrm{A} . \mathrm{h}$ at saturation with respect to the half lives of both ${ }^{99} \mathrm{Mo}$ and ${ }^{99 \mathrm{mTc}}$.

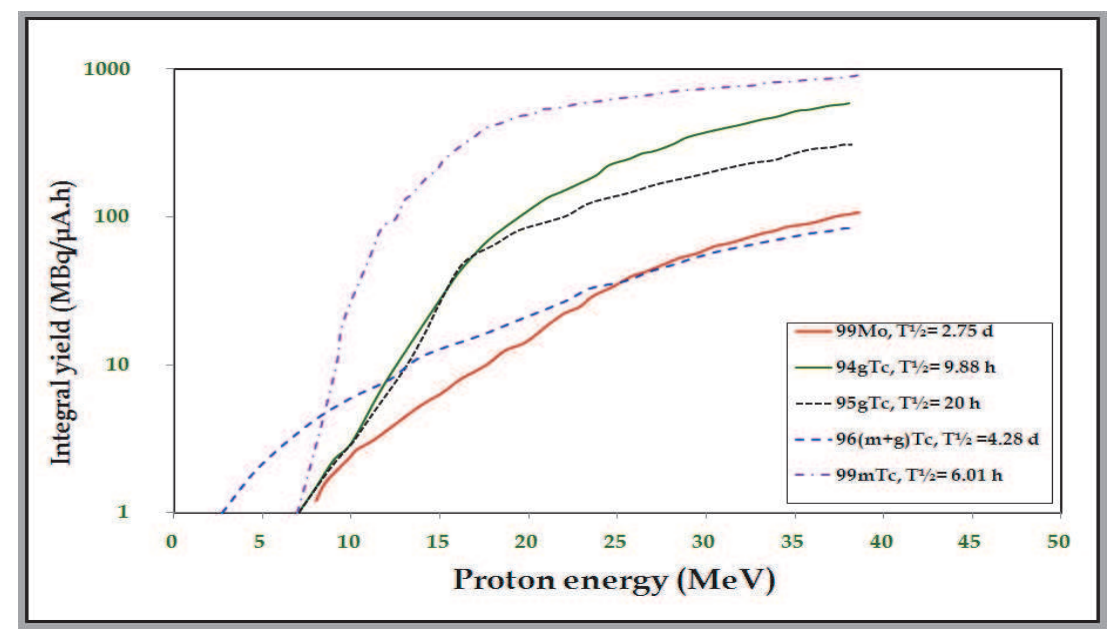

Fig. 13. Integral Yields for the natMo(p,x $)^{99} \mathrm{Mo},{ }^{94 g}, 95 \mathrm{~g}, 96(\mathrm{~m}+\mathrm{g}), 99 \mathrm{mTc}$ nuclear reactions calculated from the excitation functions measured in this work.

\section{Conclusion}

$99 \mathrm{mTc}$ radioisotope is a very important medical radioisotope for diagnostic tests. In this work an alternative root of producing this isotope, either directly or through the generator ${ }^{99} \mathrm{Mo}$ ( $99 \mathrm{mTc})$, namely using cyclotrons, is introduced and discussed. The excitation functions for the different proton-induced nuclear reactions on natMo target are measured and compared with some previously measured data. This study aims to resolve some contradictions between the existing data, and to give a reliable data set for the production of ${ }^{99 \mathrm{mTc}}$ and some other isotopes of importance in nuclear medicine beside some impurities. Monitoring reactions on $\mathrm{Al}$ and $\mathrm{Cu}$ targets are also measured and compared with the recommended IAEA data sets, in order to give high degree of consistency to our results. The present excitation functions confirm some previously measured sets, while contradict with others. Theoretical code calculations using TALYS code are performed and show a good consistency with the measured cross section values. The code calculations can be used for cross section estimations, when not enough experimental data exist. Furthermore, the integral or thick target yields are estimated based on the measured excitation functions for all the investigated reactions. Finally, it is well known that for medical uses, enriched targets have to be used in the production to avoid the secondary produced unwanted impurities. While the studies on natural targets, gives an idea about the suitable energy range for maximum production of the wanted isotope and minimum of the impurities. 


\section{Acknowledgment}

We thank G. J. Kim, D. P. May, and the staff of the CI for delivering the stable beam of protons. One of the authors Dr. A. Alharbi wish to express her appreciation to the international Fulbright U.S. exchange Scholar Program. This work was supported in part by the United States Department of Energy Office of Nuclear Physics under award number DEFG02-93ER40773, and the Texas A\&M University Cyclotron Institute.

\section{References}

Al-Saleh, F.S.; Al-Harbi, A.A. \& Azzam, A. (2006). Excitation functions of proton induced nuclear reactions on natural copper using a medium-sized cyclotron, Radiochim. Acta, 94, 391.

Audi, G.; Bersillon, O.; Blachot, J. \& Wapstra, A. H. (2003). The NUBASE evaluation of nuclear and decay properties, Nuclear Physics A, 729, 3-128.

Birattari, C.; Bonardi, M.; Gini, L.; Groppi, F. \& Menapace, E. (2002) J. Nucl. Scien. Tech., Suppl.2, 1302.

Bonardi, M.; Birattari, C.; Groppi, F. \& Sabbioni, E. (2002). Thin-target excitation functions, cross-sections and optimised thick-target yields for natMo(p,xn) ${ }^{94 g, 95 m, 95 g, 96(m+g) T c}$ nuclear reactions induced by protons from threshold up to $44 \mathrm{MeV}$. No Carrier Added radiochemical separation and quality control, Appl. Radiat. E Isot., 57, 617.

Challan, M.B.; Comsan, M.N.H. \& Abou-Zeid, M.A. (2007) Thin Target Yields and Empire-II Predictions on the accelerator production of Technetium-99m, Journal of Nuclear and Radiation Physics, 2, 1, 1-12

Fabbender, M.; Novgorodov, A.F.; Rösch, F. \& Qaim, S.M. (1994). Excitation functions of

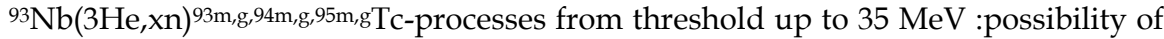
production of $94 \mathrm{~m} \mathrm{Tc}$ in high radiochemical purity using a thermo chromatographic separation technique, Radiochim. Acta, 65, 215-221.

Firestone, R.B. (1998). Table of Isotopes, $8^{\text {th }}$ edition, John Wiley \& Sons, New York, USA.

Glenn, D.; Heger, S. \& Hladik, W. (1997), Comparison of Characteristics of Solution and Conventional Reactors for Mo-99 Production, Nuclear Technology, Vol 118.

Gull, K.; Hermanne, A.; Mustafa, M.G.; Nortier, F.M.; Oblozinsky, P.; Qaim, S.M.; Scholten, B.; Shubin, Yu.; Takács, S.; Tárkányi, T.F. \& Zhuang, Y. (2001). Charged particle cross-section database for medical radioisotope production: diagnostic radioisotopes and monitor reactions, Final Report of a Co-ordinated Research Project, IAEA-TECDOC-1211, IAEA, Vienna, Austria.

Helus, F. and Colombetti, L.G. (1980). Radionuclides Production. CRC Press Inc., Boca Raton, Florida.

Hohn, A.; Zimmermann, K.; Schaub, E.; Hirzel, W.; Schubiger, P.A. \& Schibli, R. (2008). Production and separation of "non-standard" PET nuclides at a large cyclotron facility: the experiences at the Paul Scherrer Institute in Switzerland, Q. J., Nucl. Med. Mol. Imaging, 52, 145-150.

IAEA-TECDOC-1065, (1999). Production technologies for molybdenum-99 and technetium99m, IAEA, Vienna, Austria, ISSN 1011-289.

IAEA-TECDOC-468, (2009). Cyclotron produced radionuclides: physical characteristics and production methods, IAEA, Vienna, ISSN 0074-1914, ISBN 978-92-0-106908-5.

Khan, F.M. (2003).The Physics of Radiation Therapy, Third Edition, Lippincott Williams \& Wilkins, USA. 
Khandaker, M.U.; Meaze, A.K.M.M.H.; Kim, K.; Son, D.; Kim, G. \& Lee, Y.S. (2006). Measurements of the proton-induced reaction cross-sections of natMo by using the MC50 cyclotron at the Korea Institute of Radiological and Medical Sciences, J. Korean Phys. Soc., 48, 821.

Khandaker, M.U.; Uddin, M.S.; Kim, K.S.; Lee, Y.S. \& Kim, G.N. (2007). Measurement of cross-sections for the $(\mathrm{p}, \mathrm{xn})$ reactions in natural molybdenum, Nucl. Instrum. Methods Phys. Res., B 262, 171.

Koning, A. J.; Hilaire, S. \& Duijvestijn, M.C. (2008). TALYS-1.0, Proceedings of the International Conference on Nuclear Data for Science and Technology - ND2007, April 22-27, 2007, Nice, France, eds. O. Bersillon, F. Gunsing, E. Bauge, R. Jacqmin and S. Leray, EDP Sciences, 211. Available online: http://www.talys.eu/home/

Kormali, S.M.; Swindle, D.L. \& Schweikert, E.A. (1976). Charged particle activation of medium Z elements. II. Proton excitation functions, J. Radiat. Chem., 31, 437.

Krane; K.S. (1987). Introductory Nuclear Physics, John Wiley and Sons, Inc. New York, ISBN 978-812-6517-85-5, USA.

Lagunas-Solar, M.C.; Kiefer, P.M.; Carvacho, O.F.; Lagunas, C.A.; Ya Po Cha, (1991). J. Appl. Radiation Isotopes, 42, 463.

Lambrecht, R.M. \& Montner, S.M. (1982). Production and radio chemical separation of ${ }^{92} \mathrm{Tc}$ and 93Tc for PET, J. Labelled Compd. Radiopharm., 19, 1434-1435.

Levkovoskii, N. (1991). Middle mass nuclides $(A=40-100)$ activation cross sections by medium energy $(\mathrm{E}+10-50 \mathrm{MeV})$ protons and $\alpha$-particles (Experiment and Systematics). Inter-Vesti, Moscow.

Loveland, W.; Morrissey, D.J. \& Seaburg, G.T. (2006). Modern Nuclear Chemistry, John Wiley \& Sons, ISBN: 978-047-1115-32-0, USA.

Lamberecht, R.M. (1979). Positron emitting radionuclides-present and future status, Proceedings second international symposium on radiopharmaceuticals, 19-22 March, Seattle, Washington. The Society of Nuclear Medicine Inc., New York.

Nickles, R.J.; Nunn, A.D.; Stone, C.K. \& Christian, B.T., (1993). Technetium-94m -teboroximesynthesis, dosimetry and initial PET imaging studies, J. Nucl. Med., 34, 1058-1066.

Piel, H.; Qaim, S.M. \& Stöcklin, G. (1992). Excitation functions of (p,xn) reactions on natNi and highly enriched $62 \mathrm{Ni}$ - possibility of production of medically important radioisotope $62 \mathrm{Cu}$ at a small cyclotron, Radiochem. Acta, 57, 1.

Qaim, S.M.; Clark, J.C.; Crouzel, C.; Guillaume, M.; Helmeke, H.J.; Nebeling, B.; Pike, V.W. \& Stöcklin, G. (1993). PET radionuclide production. In: Radiopharmaceuticals for Positron Emission Tomography. (Stöcklin, G., Pike, V. W., Eds.), Kluwer Academic Publishers, Dordrecht, The Netherlands, pp. 1-42.

Qaim, S.M. (2000). Production of high purity $94 \mathrm{mTc}$ for positron emission tomographic studies, Nucl. Med. Biol., 27, 323-328.

Qaim, S.M. (2001). Nuclear data relevant to the production and application of diagnostic radionuclides, Radiochim. Acta, 89, pp. 223-232.

Qaim, S.M. (2003). Cyclotron production of medical radionuclides, Handbook of nuclear chemistry 4, Kluwer Academic Publishers, Dordrecht, Netherlands.

Qaim, S.M. (2004). Use of cyclotron in medicine, Radiation Physics and Chemistry, 71, pp. 917-926.

Raynal, J. (1994). Notes on ECIS-94, CEA Saclay Report No. CEA-N-2772.

Reference Input Parameter Library, Available online: http://www-nds.iaea.org/ripl2/

Rösch, F. \& Qaim, S.M. (1993). Nuclear data relevant to the production of the positron emitting technetium isotope ${ }^{94 \mathrm{mTC}}$ via the ${ }^{94} \mathrm{Mo}(\mathrm{p}, \mathrm{n})$ reaction, Radiochim. Acta, 62, 115-121. 
Rösch, F.; Novgorodov, A.F. \& Qaim, S.M. (1994). Thermo chromatographic separation of 94mTc from enriched molybdenum targets and its large scale production for nuclear medical application, Radiochim. Acta, 64, 113-120.

Sajjad, M. \& Lambrecht, R.M. (1993). Cyclotron production of medical radionuclides, Nucl. Instrum. Meth., B79, 911-915.

Scholten, B.; Lambrecht, R.M.; Cogneau, M.; Ruiz, H.V. \& Qaim, S.M. (1999). Excitation

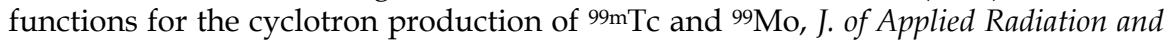
Isotopes, 51, 69-80

Sharp, P.F.; Germmell, H.G. \& Murray, A.D. (3ed.) (2005), Practical Nuclear Medicine, ISBN13: 978-1852338756, Springer-Verlag London Limited, USA.

Stőcklin, G.; Qaim, S.M. \& Rösch, F. (1995). The impact of radioactivity on medicine, Radiochim. Acta, 70/71, 249-272.

T-16, Nuclear Physics Group, Theoretical Division of the Los Alamos National Laboratory (1997). Nuclear Information Service, Los Alamos, USA. Available online: http://t2.lanl.gov/data/data.html

Takács, S.; Tárkányi, F.; Sonck, M. \& Hermanne, A. (2002). New cross sections and intercomparison of proton monitor reactions on $\mathrm{Ti}, \mathrm{Ni}$ and $\mathrm{Cu}, \mathrm{Nucl}$. Instrum. Methods Phys. Res., B 188, 106.

Takács, S.; Szúcs, Z.; Tárkányi, F.; Hermanne, A. \& Sonck, M. (2003). Evaluation of proton

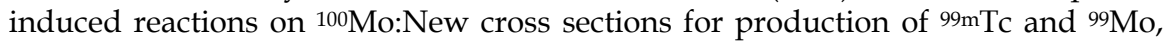
Journal of Radio analytical and Nuclear Chemistry, Vol. 257, No. 1, pp. 195.201

Tammemagi, H., Jackson, D. (2009). Half-Lives A Guide to Nuclear Technology in Canada, Oxford University Press, pp. 11-13, 156.

Tárkányi, F.; Takács, S.; Gul, K.; Hermanne, A.; Mustafa, M.G.; Nortier, M.; Obložinský, P.; Qaim, S.M.; Scholten, B.; Shubin, Yu.N. and Zhuang Y. (2001). Beam Monitor Reactions, IAEA-TECDOC-1211, IAEA, Vienna, p. 49, Updated version January, 2007. Available from: http://www-nds.iaea.org/medical

Troyer, G.L. \& Schenter, R.E. (2009). Medical isotope development and supply opportunities in the $21^{\text {st }}$ century, J. Radioanal. Nucl. Chem., 282:243-246, DOI 10.1007/s10967-009-0267-4.

Uddin, M.S.; Hagiwara, M.; Tárkányi, F.; Ditrói, F. \& Baba, M. (2004). Experimental studies on the proton-induced activation reactions of molybdenum in the energy range 22$67 \mathrm{MeV}$, Appl. Radiat. \& Isot., 60, 911.

Uddina, M.S. \& Baba, M. (2008). Proton-induced activation cross-sections of the short-lived radionuclides formation on molybdenum, Appl. Radiat. E Isot., 66,208-214.

Ullyett, B. (1997), Chapter Five - Canada Enters the Nuclear Age, published for Atomic Energy of Canada Limited, McGill-Queen's University Press.

Van der Marck, S. C., Koning, A. J. \& Charlton, K. E., (2010). The options for the future production of the medical isotope ${ }^{99} \mathrm{Mo}$, Eur J Nucl Med Mol Imaging, 37:1817-1820 DOI 10.1007/ s00259-010-1500-7

Wolf, A.P.; Barclay Jones, W. (1983). Cyclotrons for biomedical radioisotope production, Radiochim. Acta, 34, 1.

Ziegler, J.F. (1995). TRIM 95.4 code: The Transport of Ions in Matter, IBM-Research, Yorktown, New York, USA.

Ziegler, J.F.; Biersack, J.P. \& Littmark, U. (1985). The Stopping and Range of Ions in Solids. Vol. 1 of the Stopping and Ranges of Ions in Matter, Pergamon Press, New York. 


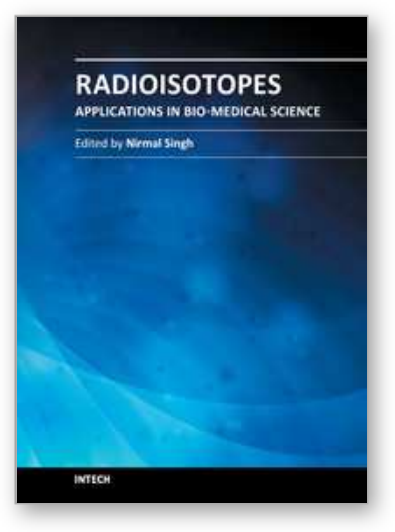

\author{
Radioisotopes - Applications in Bio-Medical Science \\ Edited by Prof. Nirmal Singh
}

ISBN 978-953-307-748-2

Hard cover, 320 pages

Publisher InTech

Published online 21, November, 2011

Published in print edition November, 2011

The book Radioisotopes - Applications in Bio-Medical Science contains two sections: Radioisotopes and Radiations in Bioscience and Radioisotopes and Radiology in Medical Science. Section I includes chapters on medical radioisotope production, radio-labeled nano-particles, radioisotopes and nano-medicine, use of radiations in insects, drug research, medical radioisotopes and use of radioisotopes in interdisciplinary fields etc. In Section II, chapters related to production of metal PET (positron emission tomography) radioisotopes, 3-dimensional and CT (computed tomography) scan, SS nuclear medicine in imaging, cancer diagnose and treatments have been included. The subject matter will by highly useful to the medical and paramedical staff in hospitals, as well as researchers and scholars in the field of nuclear medicine medical physics and nuclear biochemistry etc.

\title{
How to reference
}

In order to correctly reference this scholarly work, feel free to copy and paste the following:

A. A. Alharbi, A. Azzam, M. McCleskey, B. Roeder, A. Spiridon,E. Simmons, V.Z. Goldberg, A. Banu, L. Trache and R. E. Tribble (2011). Medical Radioisotopes Production: A Comprehensive Cross-Section Study for the Production of Mo and Tc Radioisotopes Via Proton Induced Nuclear Reactions on natMo, Radioisotopes Applications in Bio-Medical Science, Prof. Nirmal Singh (Ed.), ISBN: 978-953-307-748-2, InTech, Available from: http://www.intechopen.com/books/radioisotopes-applications-in-bio-medical-science/medicalradioisotopes-production-a-comprehensive-cross-section-study-for-the-production-of-mo-and-tc

\section{INTECH}

open science | open minds

\section{InTech Europe}

University Campus STeP Ri

Slavka Krautzeka 83/A

51000 Rijeka, Croatia

Phone: +385 (51) 770447

Fax: +385 (51) 686166

www.intechopen.com

\section{InTech China}

Unit 405, Office Block, Hotel Equatorial Shanghai

No.65, Yan An Road (West), Shanghai, 200040, China

中国上海市延安西路65号上海国际贵都大饭店办公楼405单元

Phone: +86-21-62489820

Fax: $+86-21-62489821$ 
(C) 2011 The Author(s). Licensee IntechOpen. This is an open access article distributed under the terms of the Creative Commons Attribution 3.0 License, which permits unrestricted use, distribution, and reproduction in any medium, provided the original work is properly cited. 